Catalysis Science Engineering

CSE01

New trends in (heterogeneous) catalysis in the fine chemical industry

Werner Bonrath

DSM Nutritional Products, P.O. Box 2676, CH-4002 Basel, Switzerland

For the fine chemical industry the application of catalysis is of fundamental interest. Whereas in the past the synthesis and production of fine chemicals was based on stoichiometric transformations and generated large quantities of waste, nowadays the main focus is in the development of catalytic procedures $[1,2]$. These findings follow the general trend in industrial chemistry of the use of more processes based on catalysis [3]. Main developments in the area of vitamin chemistry have been summarized in [4]. Recently several new technologies have been developed for the manufacture of fine chemicals and this is an excellent example of the long tradition of natural product synthesis carried out in Switzerland.

In the lecture, the main achievements in research and development for industrial applications for the synthesis of fine chemicals will be presented. New catalytic processes for isoprenoid synthesis, ethynylation reactions, C$\mathrm{C}$-bond formation, rearrangement reactions, hydrogenation reactions (C-C multiple bond and C-heteroatom bonds, including enantioselective hydrogenations), as well as heterocycle formation will be discussed. Furthermore, examples of new catalyst developments for the flavor and fragrance industry will be presented.

[1] W. Bonrath, Th. Netscher, Appl. Catal. A: General 2005, 280, 55.

[2] W. Bonrath, Th. Netscher, M. Eggersdorfer, Catal. Today 2007, 121, 45.

[3] A. Chauvel, B. Delmon, W.F. Hölderich, Appl. Catal. A: General 1994, $115,173$.

[4] M. Eggersdorfer, D. Laudert, U. Létinois, T. McClymont, J. Medlock, Th. Netscher, W. Bonrath, Angew. Chem. 2012, 124, 13134.
Catalysis Science Engineering

CSE02

Multicomponent Catalysts for Oxidation of Propane to Acrylic Acid developed by combinatorial approach

Gerhard Mestl

Clariant Produkte GmbH, BU Catalysis, Waldheimer Str. 13, 83052, Bruckmühl, Germany

Acrylic acid (AA) is considered as a very important monomer. There is a strong economic interest to produce AA from propane, which is much cheaper than propene applied in current two-step processes. The propane route to AA has been developed by Mitsubishi Chemical Corporation ${ }^{[1]}$ using $\mathrm{Mo}-\mathrm{V}-\mathrm{Nb}-\mathrm{Te}-\mathrm{O}$ type catalysts resulting in AA yield in the range of 50 $\%$. In further studies it has been confirmed that the high yield can be attributed to the formation of $\mathrm{M} 1$ phase responsible for $\mathrm{C}_{3} \mathrm{H}_{8}$ activation. ${ }^{[2]}$ In this study based on the composition of the M1 phase new compositions were designed. The overall goal was to get catalyst compositions exceeding $50 \%$ yield of AA. Holographic Research Strategy and ANNs were used for catalyst library design and optimization as described elsewhere. ${ }^{[3,4]}$

In this lecture details on the catalyst preparation and testing will be given. In our approach the best hit resulted in $58 \%$ yield of acrylic acid at $73 \%$ conversion. The selectivity of best hits was around $80 \%$ or above.

The above results as well as the information obtained by ANNs indicated that there are two classes of catalysts. (i) catalysts without $\mathrm{Ni}$, and (ii) catalysts containing $\mathrm{Ni}$ in the amount of $0.02-0.04 \mathrm{Ni} / \mathrm{Mo}$ ratio. Both resulted in AA yield above $55 \%$. The best compositions have been patented. ${ }^{[5]}$

[1] Ushikobo T., et al., European Patent 5281745 (1994); European Patent 529853 (1995); US Patent 5380933 (1995).

[2] Botella P., Nieto J.M.L., Solsona B., Catal. Lett. 2002,78, 383.

[3] Végvári L., et al. Catal. Today 2003, 81, 517.

[4] Tompos A., et al. Appl. Catal. A: Gen. 2005, 285, 65.

[5] DE 102011109 774.4, and DE 102011109816.3

Catalysis Science Engineering

CSE04

Catalysis Science Engineering

CSE03

New electro-catalyst alloys for the Oxygen Reduction Reaction (ORR) and Hydrogen Peroxide production.

\section{Ib Chorkendorff}

CINF, Department of Physics, DTU. DK-2800, Denmark.

There is a strong demand for improving the anode material of the Proton Exchange Membrane Fuel Cell, either by increasing the activity and thereby being able to reduce the loading or by replacing Pt entirely. Recently we have found a new class of alloys, which are very active towards the Oxygen Reduction Reaction (ORR). The first catalyst were predicted in a DFT screening study which pointed for activity and stability towards $\mathrm{Pt}_{3} \mathrm{Sc}$ and $\mathrm{Pt}_{3} \mathrm{Y}$ and the latter proved particular active by a factor 7-8 times as active as polycrystalline $\mathrm{Pt}^{[1]}$ Initially we have tested the activity of poly crystalline samples in a rotating disk setup. We have since expanded the number of catalyst to also include $\mathrm{Zr}$, Hf and $\mathrm{La},{ }^{[2,3]}$ but the most active and stable catalysts seems to be $\mathrm{Pt}_{5} \mathrm{Ga}^{[4]} \mathrm{By}$ comparison to our recent studies of $\mathrm{PtCu}$ catalyst $^{[5]}$ it is possible to identify the surface composition more accurately. The Pt and Y, La, and Gd catalysts are among the most active and stable forming a rather thick skin consisting of several monolayers of Pt. This skin is found to be under compression leading to the necessary lower binding energy of oxygen explaining the enhanced ORR activity. The skin formation has been investigated by a broad range of surface science methods and the progress concerning the combination of ORR activity and structural investigation of polycrystalline, single crystal, and mass selected nanoparticles ${ }^{[6]}$ will be discussed. In a similar approach we have very recently also found routes to selectively reduce oxygen to hydrogen peroxide. The nature of the process and the active sites will be discussed.

[1] Nature Chemistry 2009, 1, 522.

[2] Chem. Cat. Chem. 2012, 4, 341; Energy Environ. Sci., 2012, 5, 6744.

[4] J. Am. Chem. Soc. 2012, 134, 16476-16479.

[5] J. Am. Chem. Soc. 2011, 133, 5485-5491.

[6] Angew. Chem. Int. Ed. 2012, 51, 4641-4643.

\section{“Green Energy" by solar water splitting}

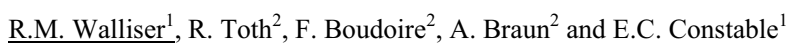

${ }^{1}$ University of Basel, Spitalstrasse 51, CH-4056 Basel, Switzerland

${ }^{2}$ EMPA, Überlandstrasse 129, CH-8600 Dübendorf, Switzerland

Energy is key to maintaining the standard of "modern life" that we know. Due to shrinking resources and increasing pollution a new and sustainable way of producing energy is needed. Hydrogen fuel induced by solar water splitting is a vision of the future which can allay our needs. Heterogeneous photocatalysts used in PECs (photoelectrochemical cells) have to possess the following properties. The light absorbing system needs to have the right energetics and thermodynamics to facilitate water decomposition into $\mathrm{H}_{2}$ and $\mathrm{O}_{2}$. The catalyst in the cell needs to have the right redox potential for effective water splitting and the system needs also to be corrosion resistant in the electrolyte. Enhanced efficiency can be found in the use of nanostructures which offer a high catalytically active surface area. Hematite nanostructures possess most of these properties [1]. In our research collaboration, reaction-diffusion precipitation known as Liesegang phenomena are being investigated because the location of the self-organized chemical pattern is locked after producing the complex. two co-precipitating inorganic salts diffuse through to certain matrices (e.g. gels) in which the precipitate forms discrete bands perpendicular to the propagation of the invading electrolyte [2]. In order to combine the phenomena with "nano" techniques, the wet stamping method a "bottom up" technique where the structures are made out of building blocks in self assembling steps for a controllable production of periodic precipitation patterns is used. This technique allows us to decrease the size of the pattern and to find new strategies to pattern hematite films for photoelectrodes.

[1] A. Braun, K. Sivula, D.K. Bora, J. Zhu, L. Zhang, M. Grätzel, J. Guo and E.C. Constable, J Phys Chem C., 2012, 116, 16870.

[2] S.K. Smoukov, I. Lagzi and B.A. Grzybowski, J. Phys. Chem. Lett., 2011, 2, 345 . 
Catalysis Science Engineering

CSE05

Ruthenium nanoparticle supported on hydrophobic sulica: a change on surface properties and reactivity

\section{$\underline{\text { K. Furman }}^{1}$, D. Baudouin ${ }^{1}$, F. Ribeiro ${ }^{2}$ and C. Coperét ${ }^{1} *$}

ETH Zürich, Department of Chemistry and Applied Biosciences, Laboratory of Surface and Interfacial Chemistry, Wolfgang-Pauli-Strasse 10, 8093 Zürich (Switzerland)

${ }^{2}$ Purdue University, School of Chemical Engineering, 480 Stadium Mall Drive, West Lafayette, N 47907-2100 (United States of America)

Supported nanoparticles (NPs) are one of the largest classes of heterogeneous catalysts and are used both in the petrochemical and the fine chemical industries. In these systems, there are numerous parameters influencing the catalyst performances, such as the size and the distribution of the metallic nanoparticles, but also their interaction with the support surface [1]. Recently Gajan et al. studied small AuNPs of ca. $2 \mathrm{~nm}$ supported on silica covered with $-\mathrm{OSiMe}_{3}$ groups instead of $\mathrm{OH}$ functionalities, which greatly modifies the hydrophobic character of the surface and the catalytic properties of $\mathrm{Au}$ [2]. We thus investigated the effect of $\mathrm{Me}_{3} \mathrm{SiO}$ - groups at the surface of silica on the reactivity and selectivity of supported $\mathrm{Ru}$ nanoparticles $\left(\mathrm{Ru} / \mathrm{SiO}_{2}\right.$ osime3) towards Water-Gas-Shift reaction. $\mathrm{Ru} / \mathrm{SiO}_{2-\mathrm{osime}}$ exhibits a four-fold increase in methanation rate in comparison to RuNPs supported on silica covered with $\mathrm{OH}$ functionalities $\left(\mathrm{Ru} / \mathrm{SiO}_{2}\right)$, which is to be related to a modification of the $\mathrm{CO}$ adsorption properties of these particles.

[1] Den Breejen et al, J. Am. Chem. Soc. 2009, 131, 7197.

[2] Gajan et al, J. Am. Chem. Soc. 2009, 131, 14667.
Catalysis Science Engineering

CSE06

\section{Steric Control at the Active Site in Organocatalysis by Phosphine Metal-Organic Frameworks}

Xiaoying Xu ${ }^{\mathrm{a}, \mathrm{b}}$ Stephan M. Rummelt, ${ }^{\mathrm{a}}$ Flavien L. Morel, ${ }^{\mathrm{a}, \mathrm{b}}$ Michael Wörle, ${ }^{a}$ Marco Ranocchiari, ${ }^{\mathrm{b}}$ Jeroen A. van Bokhoven ${ }^{\mathrm{a}, \mathrm{b}}$

a ETH Zürich, 8093 Zürich, Switzerland;

b Paul Scherrer Institute, CH-5232, Villigen PSI, Switzerland

Metal-organic frameworks (MOFs) with large porosity and high crystallinity are ideal candidates for heterogeneous catalysts. [1] We report here a rationally designed, crystalline, and porous P-functionalized MOF, named LSK-3, featuring IRMOF-9 topology (Figure).

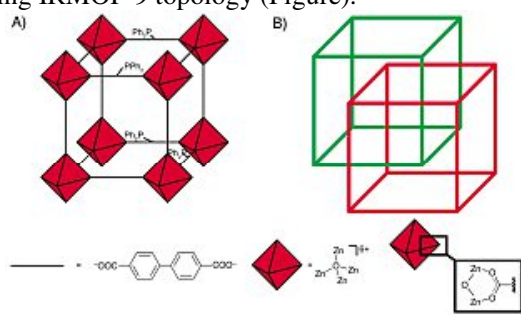

LSK-3 performed phosphine organocatalysis with a unique reaction selectivity, which has been rationalized by means of molecular modeling. The crystalline nature of the framework provides additional steric hindrance and new unexplored ways to modify the local environment of the active site. Analogously to enzymes, it is not only the size of the pores that determines the behavior of the catalyst, but it is how the active site is oriented relative to the MOF framework, which affects what substrate can and cannot react. This opens new avenues for structural control and understanding of heterogeneous catalyst fully exploiting the unique MOF properties.

[1] Ranocchiari, M. and van Bokhoven, J. A. Phys. Chem. Chem. Phys., 2011, 13, 6388

Selective $\mathrm{CeO}_{2}$-based catalysts for liquid-phase hydrogenation of triple bonds in polyunsaturated and polyfunctionalized substrates

Gianvito Vilé, Leonard Floryan, Javier Pérez-Ramírez*

\section{ETH Zurich, Wolfgang-Pauli-Strasse 10, CH-8093 Zurich, Switzerland}

It has been recently discovered that ceria exhibits a remarkable selectivity in the gas-phase hydrogenation of acetylene and propyne to the corresponding olefins [1]. Here, we have gathered further fundamental aspects of the behavior of this intriguing metal oxide in hydrogen mediated reactions. Terminal (1-pentyne, 1-hexyne) and non-terminal (2-pentyne, 3-hexyne) alkynes as well as substrates containing additional functional groups (3- methyl-1-pentyn-3-ol, phenylacetylene, ethyl-4-phenyl-2-butyn-oate) and conjugated unsaturations (2-methyl-1-buten-3-yne) have been systematically hydrogenated over $\mathrm{TiO}_{2}$-supported $\mathrm{CeO}_{2}$ in a trickle-bed micro-reactor. The results have revealed outstanding stereoselectivity, regioselectivity, and chemoselectivity patterns of ceria-based catalysts, with important implications for olefin purification and fine chemical production.

$\mathrm{HC} \equiv{\stackrel{\mathrm{CH}}{3} \mathrm{CH}_{3}}_{\mathrm{OH}}^{\mathrm{H}}$
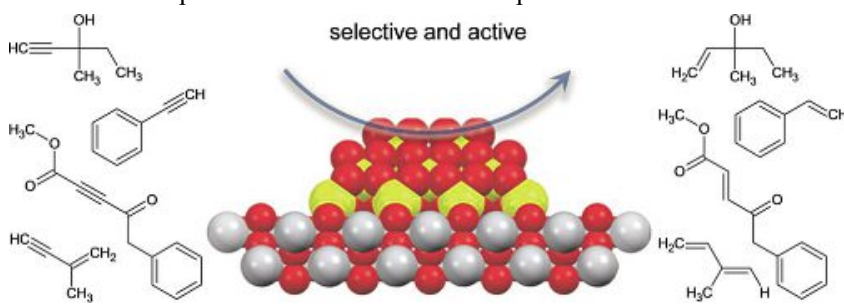

Fig. 1. Schematic representation of the selective character of $\mathrm{CeO}_{2} / \mathrm{TiO}_{2}$ in the hydrogenation of triple bonds.

[1] G. Vilé, B. Bridier, J. Wichert, J. Pérez-Ramírez, Angew. Chem. Int. Ed. 2012, 51,8620
Catalysis Science Engineering

\section{CSE08}

Reinventing zeolite base catalysis: Less is more

Tobias C. Keller, Stéphane Isabettini, Javier Pérez-Ramírez*

ETH Zurich, Wolfgang-Pauli-Strasse 10, CH-8093 Zurich, Switzerland

The use of alkali-metal ion-exchanged zeolites as catalysts for reactions requiring weak basicity has been known for more than 20 years. However, their success has been hampered by their humble activity, that was often further crippled by access limitations. Through introduction of hierarchical structuring, their performance could be improved and mesoporosity was identified as predominant performance descriptor. In this work, the role of cation type and loading along with porous structure was investigated in detail for a broad compositional range of faujasite zeolites. As a result, hierarchical high-silica zeolites were identified as outstanding base catalysts, revolutionizing the fundamental concepts behind zeolite base catalysis.

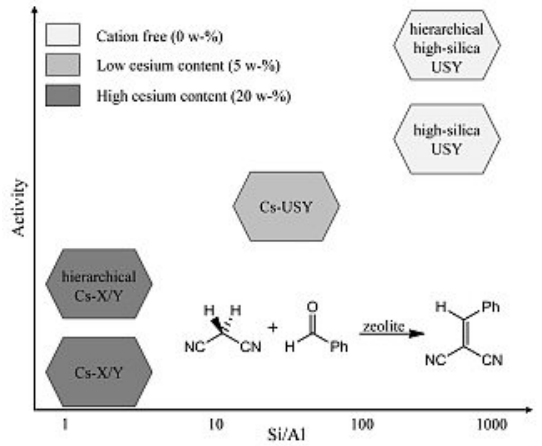

Fig. 1. Schematic of the activity of zeolite base catalysts.

[1] D. Verboekend, T. C. Keller, S. Mitchell, J. Pérez-Ramírez, Adv. Funct. Mater. 2013, 23, 1923. 
Catalysis Science Engineering

CSE09

When DFT Calculations Meet Experimental Results: Understanding the Structure Sensitivity of Alkyne Hydrogenations on Pd nanoparticles

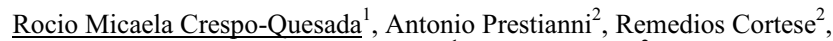 Lioubov Kiwi-Minsker ${ }^{1}$ and Dario Duca ${ }^{2}$}

${ }^{1}$ GGRC, EPFL, 1015 Lausanne, Switzerland

${ }^{2}$ Dipto. di Chimica, Università degli Studi di Palermo, 90128 Palermo, Italy

Structure sensitive reactions are characterized by showing activity and selectivity dependence on nanoparticle size and shape (i.e. the type of exposed atoms, such as $\mathrm{Pd}(111)$ or $\mathrm{Pd}(100)$ planar sites, or low coordination sites). The observed behavior may have a thermodynamic reason, i.e. a difference in the adsorption strength of the alkyne and alkene on each type of active site, or a kinetic reason, i.e. different activation energies for each step of the reaction on each site.

Therefore, we studied the hydrogenation of 2-methyl-3-butyn-2-ol (MBY) to 2-methyl-3-buten-2-ol (MBE), which is a known structure sensitive reaction [1], within a DFT based ab-initio approach on a $\mathrm{Pd}_{30}$ cluster showing both planar and low coordination sites, to gain an atomistic perspective of the phenomenon. Both the thermodynamic and kinetic drives were explored by determining firstly the adsorption strengths of all possible adsorption modes for MBY and MBE, and then the activation energies of each step of the reaction on each type of site. In order to validate the results, MBY gas-phase hydrogenations were also carried out on $\mathrm{SiO}_{2}$ well-defined supported nanocubes of 10 and $18 \mathrm{~nm}$ in edge length (enclosed by $\operatorname{Pd}(100)$ atoms) and octahedra of $37 \mathrm{~nm}$ of edge length (enclosed by $\mathrm{Pd}(111)$ atoms). The DFT analysis determined that the key to the structure sensitivity of the reaction comes from the different heats of adsorption of MBY and MBE on each type of site, rather than from a kinetic drive. This allowed making predictions concerning the activity of the different $\mathrm{Pd} / \mathrm{SiO}_{2}$ catalysts, which were subsequently confirmed by the experimental results

[1] M. Crespo-Quesada et al., J Am Chem Soc 2011, 133, 12787.
Catalysis Science \& Engineering

CSE10

Performance of a $\mathrm{Au} / \mathrm{Al}_{2} \mathrm{O}_{3}$ catalyst in the decomposition of formic acid

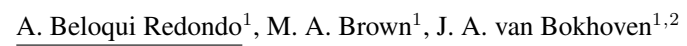

${ }^{1}$ Institute for Chemical and Bioengineering, ETH Zürich, 8093 Zurich, Switzerland

${ }^{2}$ Laboratory for Catalysis and Sustainable Chemistry, PSI, 5232 Villigen, Switzerland

After years of being used as a test reaction for catalytic activity, the decomposition of formic acid has become a potential source of $\mathrm{H}_{2}$ [1] via reaction $\mathrm{HCOOH} \longrightarrow \mathrm{H}_{2}+\mathrm{CO}_{2}$.

The undesired side reactions forming $\mathrm{CO}+\mathrm{H}_{2} \mathrm{O}$ and $\mathrm{HCHO}+\mathrm{CO}_{2}+\mathrm{H}_{2} \mathrm{O}$ are known [2,3], however the latter is often disregarded, making it unclear if its occurrence is monitored. This plays an important role in the calculation of $\mathrm{H}_{2}$ selectivity if only dehydrogenation and dehydration are taken into account.

A system to carry out the catalytic vapor-phase decomposition of $\mathrm{HCOOH}$ and to determine the conversion and selectivity to $\mathrm{H}_{2}, \mathrm{CO}_{2}$ and $\mathrm{CO}$, while being able to detect the presence of other products like formaldehyde and methanol, was developed. 0.7 wt. $\% \mathrm{Au} / \mathrm{Al}_{2} \mathrm{O}_{3}$ catalysts were synthesized and pretreated under different conditions to compare their performance in the dehydrogenation of formic acid between room temperature and $350{ }^{\circ} \mathrm{C}$.

Reducing or calcining the catalyst gave different $\mathrm{Au}$ particle sizes, yet no significant changes in conversion or $\mathrm{H}_{2}$ selectivity were observed. Full conversion was reached above $200{ }^{\circ} \mathrm{C}$ while $\mathrm{H}_{2}$ selectivity decreased from $100 \%$ at $100{ }^{\circ} \mathrm{C}$ to less than $65 \%$ at $350^{\circ} \mathrm{C}$ for all pretreated catalysts. $\mathrm{H}_{2}$ selectivity remained more stable over time for catalysts pretreated at higher temperatures. $\mathrm{CH}_{3} \mathrm{OH}$ and $\mathrm{HCHO}$ were detected with all catalysts above a reaction temperature of $130{ }^{\circ} \mathrm{C}$ and accounted for up to $35 \%$ of the products at $350{ }^{\circ} \mathrm{C}$.

[1] F. Joó, Chem. Sus. Chem. 2008, 1, 805 - 808.

[2] P. Mars, J.J.F. Scholten, and P. Zwietering, Adv. Catal. 1963, 14, 35-113.

[3] T. Kecskés, R. Németh, J. Raskó, J. Kiss, Vacuum 2005, 80, 64-68.

\section{Activity and Selectivity of Pd Catalyst in Liquid-Phase Alkynol Hydrogenation: Effect of Particle Size and Modification with the Second Metal}

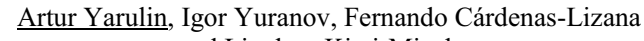
and Lioubov Kiwi-Minsker

Ecole Polytechnique Fédérale de Lausanne, GGRC-ISIC-EPFL, Lausanne CH-1015, Switzerland

Pd-catalyzed selective $-\mathrm{C} \equiv \mathrm{C}$ - hydrogenation to the corresponding olefinic product is an important reaction in the manufacture of fine chemicals. ${ }^{1}$ In this type of reactions, controlled modifications in Pd nanoparticle (NP) size and addition of a second metal were identified as effective means of influencing catalytic response. ${ }^{1,2}$ We analyzed the effect of particle size on catalyst performance for a series of monodispersed Pd NPs $(2-10 \mathrm{~nm})$ stabilized by poly(N-vinyl-2-pyrrolidone) (PVP) in the liquid-phase selective hydrogenation of alkynols with different hydrocarbon chains $\left(\mathrm{C}_{5^{-}}\right.$ $\mathrm{C}_{20}$ ). Larger Pd NPs exhibit intrinsically higher specific activity (per Pd surface atom) while smaller Pd NPs deliver greater alkenol selectivity. Experimental data are adequately represented by a kinetic model based on a Langmuir-Hinshelwood mechanism. A significant (up to $96 \%$ ) increase in selectivity to the target olefinic product at almost complete (98\%) conversion with addition of the second metal $(\mathrm{Ag}, \mathrm{Cu})$ was demonstrated over PVP-stabilized as well as supported NPs. This result is attributed to the blockage of "unselective" Pd sites responsible for over-hydrogenation. Catalytic response was rationalized by high-resolution microscopy coupled with energy-dispersive $\mathrm{x}$-ray spectroscopy.

Our findings establish the basis for the development of Pd-based catalysts for the selective production of alkenols where product distribution depends on the hydrocarbon chain length and can be controlled by adjusting the Pd NP size and the incorporation of a second metal.

[1] N. López and C. Vargas-Fuentes, Chem. Commun. 2012, 48, 1379.

[2] N. Semagina and L. Kiwi-Minsker, Catal. Rev.-Sci. Eng. 2009, 51, 47.
Advanced cathode materials based on Pt-oxide systems for application in polymer electrolyte fuel cells (PEFCs)

Emiliana Fabbri, Rüdiger Kötz, Thomas J. Schmidt

Electrochemistry Laboratory, Paul Scherrer Institut, 5232 Villigen PSI, Switzerland

One of the main drawbacks hindering a widespread commercialization of polymer electrolyte fuel cells (PEFCs) is the slow kinetics of the oxygen reduction reaction (ORR) at the cathode side and the cathode's corrosion stability. In the last years, important progresses have been made towards the development of advanced catalytic materials based on Pt-alloy nanoparticles supported on high-surface area carbons (Pt/C). However, $\mathrm{Pt} / \mathrm{C}$ systems suffer from corrosion instability, being fuel cell lifetime determining. Therefore, a growing interest is raising towards alternative, more stable support materials to carbons, such as metal oxides.

Among the stable oxides in acidic media, we have selected antimony doped tin oxides since they can achieve high electronic conductivity and are relatively low-cost materials. Doped-tin oxide has been synthesized by a modified sol gel method. The powder processing significantly influenced the dopant distribution between the bulk and the surface of the oxide particles; by means of X-ray phothoelectron spectroscopy we were able to correlate the surface chemistry of oxide semiconductors with their interfacial electrochemical properties in liquid electrolyte. On the porous oxide thin films, $\mathrm{Pt}$ nanoparticles were deposited by magnetron sputtering and cyclic voltammetry and rotating ring disc electrode (RRDE) measurements were performed to evaluate the electrochemical stability and activity towards ORR.

This work was supported by the Competence Center Energy and Mobility (CCEM), Switzerland and by Umicore AG \& Co. KG within the project DuraCat.

[1] A. Rabis, P. Rodriguez, T.J. Schmidt, ACS Catal., 2012, 2, 864-890. 
Catalysis Science Engineering

CSE13

Deactivation of a commercial honeycomb noble metal-based $\mathrm{CO}$ oxidation catalyst by $\mathrm{Cr}$-containing species

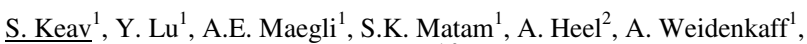

$$
\begin{aligned}
& \text { D. Ferri }{ }^{1,3}
\end{aligned}
$$

${ }^{1}$ Empa, Lab. for Solid State Chemistry and Catalysis; CH-8600 Dübendorf, Switzerland ${ }^{2}$ Empa, Marketing, knowledge and technology transfer, $\mathrm{CH}-$ 8600 Dübendorf, Switzerland; ${ }^{3}$ Paul Scherrer Institute, CH-5232 Villigen, Switzerland

Catalyst deactivation is of great concern since it is by and large unavoidable and directly impacts the efficiency and the cost of a process. One major cause of deactivation is chemical poisoning by metal- $(\mathrm{Pb}, \mathrm{Ca}, \mathrm{Zn})$ or heteroatom-containing $(\mathrm{P}, \mathrm{S})$ compounds present in the stream $[1,2]$. Under very harsh conditions (high temperature, oxidizing atmosphere and moisture), even highly stable stainless steel can be corroded, releasing volatile $\mathrm{Cr}(\mathrm{VI})$-containing species [3]. In the present work, a commercial honeycomb noble metal-based catalyst was exposed for 7'300 h to a stream containing $\mathrm{CO}$ and volatile $\mathrm{Cr}$-based species. The significantly lower activity of the spent catalyst was attributed to the coverage of noble metal particles, predominantly by $\mathrm{Cr}_{2} \mathrm{O}_{3}$ and $\mathrm{CrO}_{2}$. The $\mathrm{CO}$ conversion temperature range and the conversion profiles were similar to those obtained on mixed $\mathrm{Al}_{2} \mathrm{O}_{3}$ $\mathrm{Cr}_{2} \mathrm{O}_{3}$ catalysts [4], thus confirming the role of the Cr-containing species. The inhomogeneous distribution of the deposit along the monolith channels resulted in the different sections (inlet, middle, outlet) of the spent catalyst to have different activities, the inlet section being the most strongly deactivated.

[1] S.K. Matam, E.H. Otal, et al., Catal. Today, 2012, 184, 237.

[2] S.Y. Christou, S. García-Rodríguez, et al., Appl. Catal. B, 2012, 111, 233.

[3] K. Hilpert, D. Das, et al., J. Electrochem. Soc., 1996, 143, 3642.

[4] T.P. Maniecki, Catal. Today, 2011, 176, 215.

Catalysis Science Engineering

\section{Cycloaddition of $\mathrm{CO}_{2}$ to Epoxides Catalyzed by \\ Imidazolium-Based Polymeric Ionic Liquids}

Saeideh Ghazali-Esfahani, Hongbing Song, Emilia Paunescu, Félix Daniel Bobbink, Huizhen Liu, Zhaofu Fei, Paul J. Dyson

Institut des Sciences et Ingénierie Chimiques, Ecole Polytechnique Fédérale de Lausanne (EPFL), CH-1015 Lausanne, Switzerland.

Conversion of carbon dioxide $\left(\mathrm{CO}_{2}\right)$ into useful chemicals has attracted considerable interest. Cycloaddition of $\mathrm{CO}_{2}$ to epoxides affording more valuable cyclic carbonate is one of the most studied catalytic systems.[1]

We prepared a styrene-functionalized imidazolium chloride polymer and studied its catalytic activity in cycloaddition of $\mathrm{CO}_{2}$ with a series of epoxides. Under mild conditions ( 40 bar pressure of $\mathrm{CO}_{2}, 140^{\circ} \mathrm{C}$ ), high yield with excellent selectivity of the cyclic carbonate can be achieved.

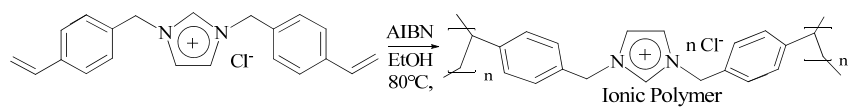

Due to the cross-linked nature, the ionic polymer is insoluble in any solvents and is highly stable, allowing easy recycling of the catalyst.

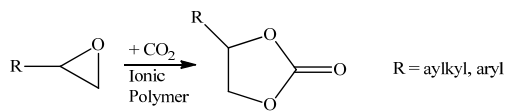

[1] Y. Xie, Z. Zhang, T. Jiang, J. He, B. Han, T. Wu, K. Ding, Angew. Chem. Int. Ed., $\mathbf{2 0 0 7}, 46,7255$.
Catalysis Science Engineering

CSE14

NanoRu@hectorite: A Heterogeneous Catalyst with Switchable Selectivity for the Hydrogenation of Quinoline

Bing Sun, Farooq-Ahmad Khan, Armelle Vallat, Georg Süss-Fink*

Université de Neuchâtel, Avenue de Bellevaux 51, CH-2000 Neuchâtel, Switzerland

The hydrogenation of quinoline is an important reaction, since the hydrogenation products have various industrial applications ranging from the production of petrochemicals and fine chemicals to the development of heterocyclic skeletons for pharmaceuticals and agrochemicals.

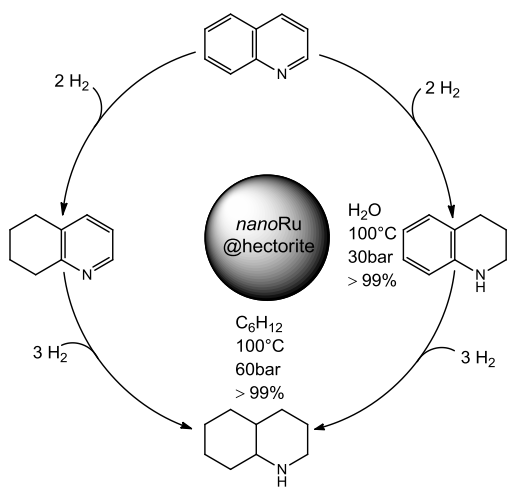

A versatile nano-structured catalyst composed of ruthenium nanoparticles intercalated in hectorite (nanoRu@hectorite) catalyzes the hydrogenation of quinoline with switchable selectivity: In water, the reaction gives 1,2,3,4-tetrahydroquinoline exclusively, while decahydroquinoline is obtained exclusively in cyclohexane.

Catalysis Science and Engineering

CSE16

DFT investigations of $\mathrm{Ni} / \mathrm{Al}_{2} \mathrm{O}_{3}$ catalyst during methanation

Izabela Czekaj, Johannes Zarfl, Joerg Wambach

Paul Scherrer Institute, Villigen, Switzerland izabela.czekaj@psi.ch

Recently, surface modifications on a commercial $\mathrm{Ni} / \mathrm{Al}_{2} \mathrm{O}_{3}$ catalyst during the production of methane from synthesis gas were investigated by quasi in-situ X-ray photoelectron spectroscopy (XPS) [1, 2]. The purpose of this study was to investigate the sulphur deactivation mechanism during an industrial methanation process, but also after catalyst regeneration.

In the present work we extended our computational investigations to study the adsorption of $\mathrm{CO}$ and $\mathrm{C}_{\mathrm{x}} \mathrm{H}_{\mathrm{y}}$ compounds on the $\mathrm{Ni} / \mathrm{Al}_{2} \mathrm{O}_{3}$ catalyst. The focus was to study possible catalyst changes and the thus modified catalytical behaviour of the nickel particles, as well as to see differences in the vibration behaviour of adsorbates, when $\mathrm{CO}$ and $\mathrm{C}_{\mathrm{x}} \mathrm{H}_{\mathrm{y}}$ adsorbs either on the variety of Ni particle sites or on the support. This was done using Density Functional Theory calculations (StoBe) with cluster model and non-loca functional (RPBE) approach. For modelling the catalyst, an $\mathrm{Al}_{15} \mathrm{O}_{40} \mathrm{H}_{35}$ cluster has been selected representing the $\gamma-\mathrm{Al}_{2} \mathrm{O}_{3}(100)$ surface, and Ni metal particles of different sizes were cut from a Ni(100) surface and deposited on the $\mathrm{Al}_{15} \mathrm{O}_{40} \mathrm{H}_{35}$ cluster. Several adsorbates have been suggested by DRIFTS studies to be stable on $\mathrm{Ni}$ /alumina support such as $\mathrm{CO}, \mathrm{C}_{2} \mathrm{H}_{2}$, or hydrogen carbonates.

\section{References}

[1] I. Czekaj, F. Loviat, F. Raimondi, J. Wambach, S. Biollaz, A. Wokaun; Appl. Catalysis A: General 329 (2007) 68-78.

[2] F. Loviat, I. Czekaj, J. Wambach, A. Wokaun; Surf. Sci. 603 (2009) 2210-2217. 
Catalysis Science Engineering

CSE17

\section{Gold mesitylene as a precursor for nanoparticle deposition}

\section{Georges Siddiqi, Victor Mougel, Christophe Copéret}

Department of Chemistry, ETH Zurich, Wolfgang-Pauli Str. 10, 8093, Zurich, Switzerland

Though gold is usually a catalytically inert material, nanoscale $\mathrm{Au}$ supported on $\mathrm{TiO}_{2}$ has been shown to be catalytically active for CO oxidation, and recently even $\mathrm{Au}$ supported on an inert support such as $\mathrm{SiO}_{2}$ has shown intrinsic activity for CO oxidation. $[1,2]$ The challenge with the generation of supported nanoparticles lies in obtaining contaminant free $2 \mathrm{~nm}$ particles.

We report a unique, low temperature method for the deposition of $\mathrm{Au}$ nanoparticles on $\mathrm{SiO}_{2}$ and $\mathrm{TiO}_{2}$. Via heating in an $80 \mathrm{C}$ solution of gold mesitylene and toluene, $\mathrm{Au}$ was deposited on partially dehydroxylated $\mathrm{SiO}_{2}$ with a particle size of $1.76 \pm 0.28 \mathrm{~nm}$ (Figure 1). Upon contact at $25^{\circ} \mathrm{C}$ with hydroxylated anatase $\mathrm{TiO}_{2}$, gold mesitylene in toluene was decomposed to form $<1 \mathrm{~nm}$ Au nanoparticles.

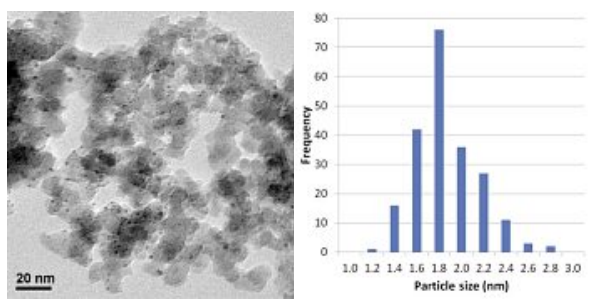

Figure 1 - TEM micrograph of Au nanoparticles deposited on $\mathrm{SiO}_{2}$ (left) and particle size distribution of $\mathrm{Au}-\mathrm{SiO}_{2}$ (right)

[1] Haruta et al., J. Catal., 1993, 144, 175

[2] Gajan et al., J. Amer. Chem. Soc. 2009, 131, 14667
Catalysis Science Engineering

CSE18

\section{Asymmetric C-H activation using Biotinylated $\mathrm{Rh}(\mathrm{I})$ Complexes}

\author{
Anamitra Chatterjee, Thomas R. Ward*
}

University of Basel, Spitalstrasse 51, CH-4056 Basel, Switzerland

Rhodium(III) complexes bearing Cp ligands proved to be highly enantioselective catalysts for directed carbon-hydrogen $(\mathrm{C}-\mathrm{H})$ bond functionalizations of hydroxamic acid derivatives. The Rh(III) catalyst generated in situ by oxidation from Rh (I) precursor was proposed to be the active and robust catalyst by Ye and Cramer [1]. Previous work proved that high levels of both selectivity and reactivity can be achieved by an artificial metalloenzyme by introducing a basic carboxylate residue in appropriate proximity to the metal center within the protein through computational modeling and genetic engineering [2]. Our current efforts are centered on the asymmetric $\mathrm{C}-\mathrm{H}$ activation relying on a coordinatevely saturated $\mathrm{Rh}$ (I) precursor incorporated in streptavidin mutants in the presence of cellular extracts.

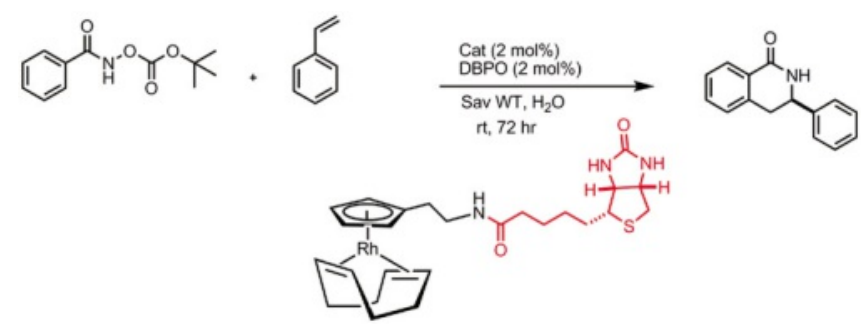

[1] B. Ye, N. Cramer, Science 2012, 338, 504.

[2] T. K. Hyster, L. Knörr, T. R. Ward, T. Rovis, Science 2012, 338, 500.

Catalysis Science and Engineering

CSE20

Structural and electrochemical investigation of thin platinum films fabricated by pulsed laser deposition

$\underline{\text { S.E. Temmel }}^{1,2}$, E. Fabbri ${ }^{1}$, R. Kötz ${ }^{1}$, D. Pergolesi ${ }^{2}$, T. Lippert ${ }^{2}$, T.J. Schmidt ${ }^{1}$

1. Electrochemistry Laboratory, Paul Scherrer Institut, 5232 Villigen PSI, Switzerland

2. Material Science Group, Paul Scherrer Institut, 5232 Villigen PSI, Switzerland

At present, Pt-based electrocatalysts are the material of choice in polymer electrolyte fuel cells. However, due to the sluggish kinetics of the oxygen reduction reaction occurring at the cathode side, leading to overpotentials of around $0.4 \mathrm{~V}$, their wide-ranged application is still limited. Enhancing the catalytic activity by tailoring the crystallographic orientation of the surface or the electronic properties of platinum has attracted a great deal of interest over the last decade.

First steps in fabricating a new Pt-based electrocatalyst are described in this contribution. Very thin platinum films $(\sim 5 \mathrm{~nm})$ were grown on single crystalline (100) strontium titanate substrates using pulsed laser deposition. In-situ reflection high energy electron diffraction was applied to follow the growth behaviour. The effect of different deposition parameters on the surface morphology and crystalline orientation were investigated by the means of scanning electron microscopy and $\mathrm{x}$-ray diffraction. Cyclic voltammetry measurements on the produced platinum films were carried out in several electrolytes with varying $\mathrm{pH}$ and varying adsorbing anions anions in order to probe its surface properties for electrocatalytic reactions.

\section{Active sites in Re-based alkene catalysts supported on $\gamma-\mathrm{Al}_{2} \mathrm{O}_{3}$ : Structure and Density.}

Maxence Valla ${ }^{1}$, Raphael Wischert ${ }^{1}$, Matthew Conley ${ }^{1}$, Christophe Copéret $^{1}$, Philippe Sautet ${ }^{2}$.

${ }^{1}$ Institute for Inorganic Chemistry, ETH Zürich, Wolfgang-Pauli-Strasse 10,

${ }^{2}$ Institute of Chemistry, University of Lyon, Ecole Normale Supérieure of Lyon, 46, Allée d'Italie, 69364 Lyon 07, France.

While $\mathrm{Re}_{2} \mathrm{O}_{7} / \gamma$-alumina is an active room temperature catalyst in alkene metathesis, the structure of the active sites is still unknown despite forty years of research. [1] Previous studies on the model system $\mathrm{CH}_{3} \mathrm{ReO}_{3} / \mathrm{Al}_{2} \mathrm{O}_{3}$ have revealed that the active site is based on $\mathrm{Al}-\mathrm{CH}_{2}-\mathrm{ReO}_{3}(\mathbf{1})$, which results from the activation of the $\mathrm{C}-\mathrm{H}$ bond of $\mathrm{CH}_{3} \mathrm{ReO}_{3}$ on the defect sites of alumina, and which generates the catalytically active carbene (2) in the presence of alkenes.[2]

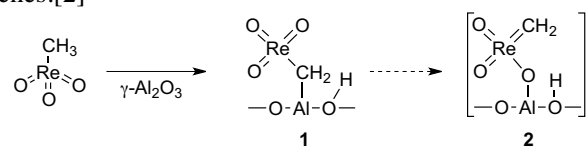

Here, we address the structure of active sites and reaction intermediates in alumina supported Re-based alkene metathesis, and also link the activity of the catalyst with the different sites of $\gamma$-alumina by a combined used of solid-state NMR spectroscopy and computational chemistry.

[1] A. Salameh, C. Copéret, J.-M. Basset et al., Adv. Synth. Catal. 2007, $349,238-242$

[3] A. Salameh, Jérôme Joubert, Anne Baudouin et al., Angew. Chem. Int. Ed., 2007, 46, 3870-3873 CH-8093 Zürich, Switzerland. 
Catalysis Science Engineering

CSE21

\section{Chemoselective Liquid Phase Hydrogenation of Nitro Aromatic Compounds over Quasi Monodispersed Pt Nanoparticles Tailored by Hyper-Crosslinked Polystyrene}

Charline Berguerand, Fernando Cárdenas-Lizana, Igor Yuranov, and Lioubov Kiwi-Minsker

Groupe du Génie de la Réaction Chimique (GGRC),

Ecole Polytechnique Fédérale de Lausanne (EPFL), CH-1015 Lausanne

Aromatic amino compounds are extensively used in the manufacture of fine chemicals [1]. The hydrogenation of nitroarenes over conventional noble metal nano-particles (NP) is known to be structure sensitive [2] meaning that a catalytic response depends on the NP surface structure. Therefore, to develop an effective catalyst, metal NPs' size has to be strictly controlled.

We report for the first time $99.9 \%$ yield of aminocompounds and high TOFs (up to $61 \mathrm{~s}^{-1}$ ) in the liquid phase hydrogenation of several para-substituted nitroaromatics $\left(-\mathrm{OH},-\mathrm{OCH}_{3},-\mathrm{CH}_{3},-\mathrm{H},-\mathrm{Br},-\mathrm{Cl},-\mathrm{COOH}\right.$ and $\left.-\mathrm{NO}_{2}\right)$ over quasi-monodispersed (ca. $3.3 \mathrm{~nm}$ from microscopy and $\mathrm{CO}$ chemisorption) Pt nanoparticles (NPs) confined within a hyper cross-linked polystyrene (HPS) polymeric matrix (uniform pore size $\sim 4.6 \mathrm{~nm} ; 1065 \mathrm{~m}^{2} \mathrm{~g}^{-1}$ ). Taking the selective hydrogenation of $p$-chloronitrobenzene as a model reaction, antipathetic structure sensitivity (i.e. up to a 3-fold TOF greater over larger, $1.6 \rightarrow 3.3 \mathrm{~nm}, \mathrm{Pt}$ NPs) has been established. Moreover, a higher activity and amine selectivity were attained at elevated pressures $(1 \rightarrow 20$ bar $)$ irrespective of the support (i.e. active carbon, $\mathrm{Al}_{2} \mathrm{O}_{3}$ and HPS). Nonetheless, while $\mathrm{Pt} / \mathrm{HPS}$ shows high stability without any activity/selectivity loss in repeated reaction runs, the state-of the-art active carbon and alumina-supported $\mathrm{Pt}$ catalysts underwent a decrease in activity as a result of metal leaching. Our results demonstrate the potential of HPS as a suitable support for tailoring metal nanoparticle size and circumvent undesirable metal leaching.

[1] H. U. Blaser, H. Steiner, M. Studer, ChemCatChem 1 (2009) 210.

[2] F. Cárdenas-Lizana, et al., J. Catal., 301 (2013) 103

Catalysis Science and Engineering

\section{Preparation of silica supported well-defined rhodium and iridium} surface dimeric complexes and their conversion into nanoparticles.

\section{F. Héroguel, D. Gebert, C. Copéret*}

ETH Zürich, Wolfgang-Pauli-Str. 10, 8093 Zürich, Switzerland.

In this study, we prepared rhodium and iridium nanoparticles via Surface Organometallic Chemistry (SOMC). The first step consists in the controlled grafting on partially dehydroxylated silica of an organometallic precursor, here $[(\mathrm{cod}) \mathrm{MOSiOR}]_{2}\left(\mathrm{M}=\mathrm{Rh}\right.$ or $\mathrm{Ir} ; \mathrm{R}=\mathrm{Me}$ or $\left.\mathrm{Si}(\mathrm{O} t \mathrm{Bu})_{3}\right)$, where a bond between the metal center and the surface is formed, with a control of the nature and density of surface sites. The supported nanoparticles are then obtained by the subsequent treatment under static or flowing hydrogen at temperatures ranging from $300{ }^{\circ} \mathrm{C}$ to $500^{\circ} \mathrm{C}$. This controlled surface chemistry leads to the formation of small nanoparticles (mean size below $2 \mathrm{~nm}$ ), where the intermediate and the final object have been characterized by ${ }^{1} \mathrm{H}$ and ${ }^{13} \mathrm{C}$ solid state NMR, infrared transmission spectroscopy, elemental analysis, transmission electronic microscopy and gas adsorption.

Rhodium and iridium catalysts were also prepared by the traditional incipient wetness impregnation technique, where the metallic precursor is dissolved in a solvent to achieve uniform dispersion on the support, and after drying the solid, the ligands are decomposed by thermal treatment and the metal is reduced by reaction with hydrogen. Influence of the preparation route on the properties of the supported nanoparticles are discussed, notably in term of hydrogen and carbon monoxide chemisorption stoichiometries.

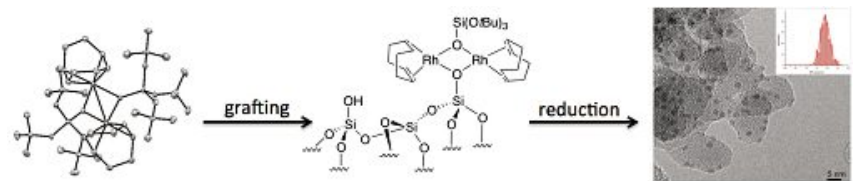

Fig. 1: Controlled grafting of $\left[(\operatorname{cod}) \mathrm{RhOSi}(\mathrm{O} t \mathrm{Bu})_{3}\right]_{2}$ on silica and its conversion into nanoparticles
Catalysis Science Engineering

CSE22

\section{Towards Directed Evolution of an Artificial Transferhydrogenase}

\section{Marc Dürrenberger, Yvonne Wilson}

Department of Inorganic Chemistry, University of Basel, Spitalstrasse 51, 4056 Basel, Switzerland

The incorporation of a biotinylated iridium piano stool complex into streptavidin (SAV) variants affords artificial transfer hydrogenases (ATHases) which have been shown to be effective catalysts for the enantioselective reduction of prochiral imines. ${ }^{[1]}$

Since the amino acids forming the second coordination sphere around the metal have a big influence on the catalytic performance, the implementation of a directed evolution protocol would be desirable. This approach would allow to screen large SAV libraries with respect to the activity and selectivity of the corresponding ATHases. In this context, two main challenges have been identified: First, methodologies have to be developed to perform catalysis in the presence of whole cells or cell lysates rather than using purified SAV. Secondly, suitable high-throughput screening assays need to be developed to allow the screening of thousands of ATHase variants directly in cell cultures. Herein, we present our efforts towards addressing these challenges

[1] Dürrenberger et al., Angew. Chem., Int. Ed. 2011, 50, 3026.

Tailoring Pd-nanoparticles selectivity via Colloidal Techniques

D. Lamey, I. Prokopyeva, F. Cárdenas-Lizana, I. Yuranov, L. Kiwi-Minsker

Ecole Polytechnique Fédérale de Lausanne, GGRC-ISIC-EPFL, CH-1015 Lausanne, Switzlerand

Synthesis of monodispersed colloidal nanoparticles (NPs) for catalytic applications is an area of research that is attracting appreciable research activity $[1,2]$. Modifications in the electronic character and/or structural properties (shape and size) of the metal NP have proved an effective means of influencing activity and selectivity in hydrogenations [2] which, in turn, can be affected by the use of specific protective and modifying agents.

We propose in this work a systematic adjustment of the surface properties of Pd NPs by means of altering the nature of the reducing, stabilizing and modifying agents. Incorporation of these agents was carried out using two approaches: $(i)$ during colloid preparation; (ii) impregnation of the catalyst support. Using a structured catalyst based on monodispersed Pd NPs supported on carbon nanofibers (CNF) grown sintered metal fibers (SMF) we have addressed the effect of metal crystal size for Pd NPs $\leq 4 \mathrm{~nm}$ where the selective hydrogenation of acetylene (to ethylene), with fundamental industrial importance, has been selected as model reaction.

The findings of this work illustrate, for the first time, that a catalyst based on polyethyleneimine (PEI, i.e. N-containing) modified CNF/SMF supported (4 nm) polyvinylpyrrolidone (PVP)-stabilized Pd is an optimum formulation for olefin production $\left(S_{\mathrm{C}_{2} \mathrm{H}_{4}}=93 \%\right)$ where the catalyst shows remarkable stability with time-on-stream. Our results illustrate the viability of fine tuning catalytic response in selective semi-hydrogenation by means of using protective/modifying agents for metal NPs.

[1] C.-J. Jia, F. Schüth, Phys. Chem. Chem. Phys. 2011, 13, 2457.

[2] N. Semagina, L. Kiwi-Minsker, Catal. Rev.-Sci. Eng. 2009, 51, 147. 
Catalysis Science Engineering

CSE25

Tuning 2nm-Ruthenium Nanoparticles Perfromances in FischerTropsch by modifying the Catalyst-Support interface

$\underline{\text { T.Margossian, K. Furman }}{ }_{1}$, D. Baudouin and C. Coperét ${ }_{1} *$

${ }_{1}$ ETH Zürich, Department of Chemistry and Applied Biosciences, Laboratory of Surface and Interfacial Chemistry, Wolfgang-Pauli-Strasse 10, 8093 Zürich (Switzerland)

Ruthenium nanoparticles (RuNPs) supported on silica exhibit high activity and selectivity in Fischer-Tropsch synthesis [1]. Recently, we discovered that the modification of the silica surface composition from standard $-\mathrm{OH}$ functionality to $-\mathrm{OSiMe}_{3}$, the adsorption properties and catalytic performance of supported RuNPs on changes significantly. The catalyst covered with $-\mathrm{OSiMe}_{3}$ groups, shows ehnaced selectivity towards oxygenated species (alcohols, aldehydes) [2], compared to the standard -OH covered catalyst, which is related to a modification of the $\mathrm{CO}$ adsorption properties of these particles.

In this work, we investigated the impact of different grafted groups on silica surface (-OSiMe $2\left(\mathrm{C}_{12} \mathrm{H}_{25}\right), \mathrm{OSiMe}_{2}\left(\mathrm{C}_{6} \mathrm{H}_{5}\right)$, etc.) towards the $\mathrm{H}_{2}$ and $\mathrm{CO}$ adsorption properties.
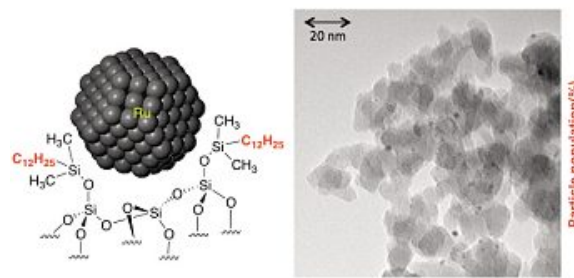

[1] D.LKing ,J.Catalysis. 1978, 51.3.386-397

[2] K.Furman, D. Baudouin and C. Coperét, Work In Progress
Catalysis Science Engineering

CSE26

Nickel-silicide colloid prepared under mild conditions as a versatile $\mathrm{Ni}$ precursor for more efficient $\mathrm{CO}_{2}$ reforming of $\mathrm{CH}_{4}$ catalysts.

David Baudouin, ${ }^{1,2}, \dagger$ Kaï Szeto, ${ }^{1}$ Aimery De Mallmann, ${ }^{1}$ Laurent Veyre, ${ }^{1}$ Uwe Rodemerck, ${ }^{3}$ Christophe Copéret, ${ }^{1,2, \dagger^{\prime}, *}$ Chloé Thieuleux ${ }^{1, *}$.

1 Université de Lyon, ICL, C2P2 UMR 5265, CPE Lyon, 43 Bd du 11 Novembre 1918, F-69616, Villeurbanne, France

2 ETH Zürich, Department of Chemistry, Laboratory of Surface and Interfacial Chemistry, Wolfgang-Pauli-Strasse 10, 8093 Zürich (Switzerland)

3 Leibniz Institute for Catalysis at University Rostock, Albert-EinsteinStraße 29a D-18059 Rostock, Germany.

Preparing highly active and stable non-noble metal-based dry reforming catalysts remains a challenge today. In this context, supported nickel nanoparticles with a size of $1.3 \pm 0.2 \mathrm{~nm}$ and $2.1 \pm 0.2 \mathrm{~nm}$ were synthetized on silica and ceria, respectively, via a two step-colloidal approach. 2-nm nickelsilicide colloids were first synthetized from $\mathrm{Ni}(\mathrm{COD})_{2}$ and octylsilane at low temperature and subsequently dispersed onto supports prior to reduction under $\mathrm{H}_{2}$. The resulting catalysts display high activity in dry reforming compared to their analogues prepared using conventional approaches, ceria providing greatly improved catalyst stability.

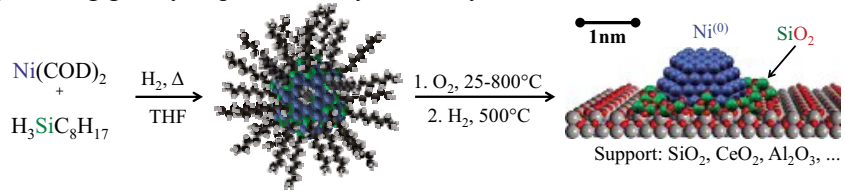

[1] D. Baudouin, K. C. Szeto, P. Laurent, A. De Mallmann, B. Fenet, L. Veyre, U. Rodemerck, C. Copéret and C. Thieuleux, J. Am. Chem. Soc., 2012, 134, 20624
Catalysis Science Engineering

CSE27

$\mathrm{CuCrO}_{2}$ delafossite: the first stable copper catalyst for $\mathrm{Cl}_{2}$ production

\author{
Amol P. Amrute, Gastón O. Larrazábal, Cecilia Mondelli, \\ Javier Pérez-Ramírez
}

ETH Zurich, Wolfgang-Pauli-Strasse 10, CH-8093 Zurich, Switzerland

The catalyzed oxidation of $\mathrm{HCl}$ to $\mathrm{Cl}_{2}$ is a highly demanded route to valorize the $\mathrm{HCl}$ surplus in the chemical industry [1]. Albeit highly active and stable $\mathrm{RuO}_{2}$-based catalysts have been piloted and installed for this reaction, the challenge to develop industrial copper-based catalysts is very appealing due to its cost-effectiveness. However, since the implementation of $\mathrm{CuCl}_{2}$ by Deacon in 1868 , the search for stable copper catalysts has been to no avail. We have discovered the first copper-based material, $\mathrm{CuCrO}_{2}$ delafossite, which exhibits high activity and most importantly unique stability under chlorinating and oxidizing conditions (Fig. 1a, b), thus, securing a stable $\mathrm{Cl}_{2}$ production in a long run. Contrarily, other cuprous delafossites such as $\mathrm{CuAlO}_{2}, \mathrm{CuGaO}_{2}, \mathrm{CuFeO}_{2}$, and $\mathrm{CuMnO}_{2}$ suffered from significant bulk changes and extensive metal loss. Building on this result, a novel $\mathrm{CuCrO}_{2}-\mathrm{CeO}_{2}$ composite is developed, which exemplified four-fold activity increase compared to its individual components (Fig. 1c) due to synergistic interaction of $\mathrm{CeO}_{2}$ with $\mathrm{CuCrO}_{2}$. Thus, a cost-effective and energy-efficient technology for chlorine recovery can now be feasible.
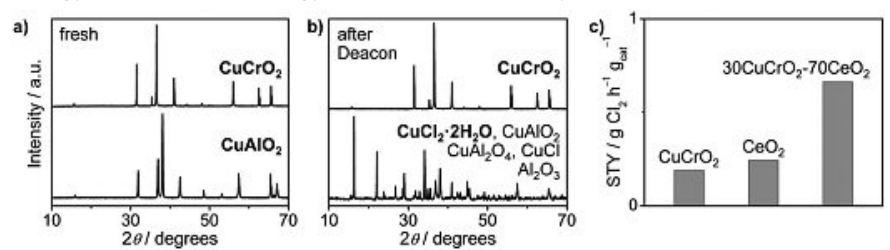

Fig. 1. XRD patterns of $\mathrm{CuCrO}$, and $\mathrm{CuAlO}_{2}$ in fresh form (a) and after Deacon (b). Space Time Yield of $\mathrm{CeO}_{2}, \mathrm{CuCrO}_{2}$, and $\mathrm{CuCrO} \mathrm{C}_{2}-\mathrm{CeO}_{2}$ (c).

[1] J. Pérez-Ramírez, C. Mondelli, T. Schmidt, O. F. -K. Schlüter, A. Wolf, L. Mleczko, T. Dreier, Energy Environ. Sci. 2011, 4, 4786.
Catalysis Science Engineering

CSE28

Rational strategies to design a technical $\mathrm{IrO}_{2}$-based Deacon catalyst

Maximilian Moser, Atsushi Tazawa, Amol P. Amrute, Cecilia Mondelli, Javier Pérez-Ramírez

ETH Zurich, Wolfgang-Pauli-Strasse 10, CH-8093 Zurich, Switzerland

The catalyzed oxidation of $\mathrm{HCl}$ to $\mathrm{Cl}_{2}$ (Deacon reaction) comprises a sustainable route to recycle chlorine in the chemical industry [1]. We discovered $\mathrm{IrO}_{2}$ as a Deacon catalyst, whose performance was further enhanced by supporting on $\mathrm{TiO}_{2}$-rutile (r). However, for the application in large-scale facilities, the technical catalyst has to fulfill additional requirements, such as a sufficient mechanical stability and preservation of the textural properties. The direct extrusion of $\mathrm{TiO}_{2}$-r yields suboptimal carriers. However, the addition of $20 \mathrm{wt} . \% \mathrm{TiO}_{2}$-anatase (a) as extrusion aid was identified beneficial. The mixed $\mathrm{TiO}_{2}$ extrudates exhibited a reasonable mechanical strength and, owing to lower calcination temperatures required, preserved most of the porosity (Fig. 1a). The obtained technical catalyst is not affected by diffusion limitation, and, in crushed form, possesses a similar activity as that of pure $\mathrm{IrO}_{2} / \mathrm{TiO}_{2}-\mathrm{r}$ (Fig. 1b). Our results on shaping strategies provide fundamental insights to rationalize the design of technical catalysts for $\mathrm{HCl}$ oxidation.
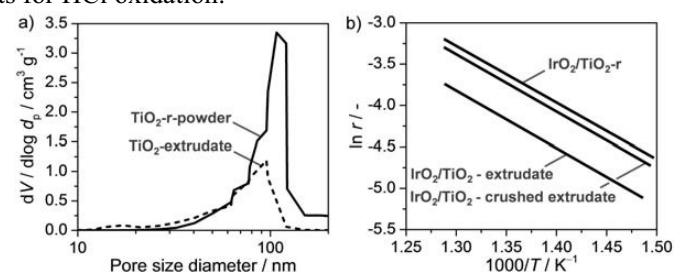

Fig. 1. (a) Pore size distribution of $\mathrm{TiO}_{2}-r$ powder and mixed $\mathrm{TiO}_{2}$ extrudates. (b) Arrhenius plot of supported and technical $\mathrm{IrO}_{2}$-based catalysts. [1] J. Pérez-Ramírez, C. Mondelli, T. Schmidt, O. F.-K. Schlüter, A. Wolf, L. Mleczko, T. Dreier, Energy Environ. Sci. 2011, 4, 4786. 
Catalysis Science Engineering

CSE29

Silver nanoparticles for olefin production: a paradigm shift in the mechanistic description of catalyzed hydrogenations

Gianvito Vilé $^{1}$, David Baudouin ${ }^{1}$, Christophe Copéret ${ }^{1}$, Núria López ${ }^{2}$, Javier Pérez-Ramírez, ${ }^{1, *}$

${ }^{1}$ ETH Zurich, Wolfgang-Pauli-Strasse 10, CH-8093 Zurich, Switzerland ${ }^{2}$ ICIQ, Av. Països Catalans 16, E-43007 Tarragona, Spain

The selective hydrogenation of unsaturated hydrocarbons is crucial for the purification of olefin streams and the manufacture of fine chemicals. The development of novel heterogeneous catalysts excelling the performance of available Pd-based systems constitutes a key challenge requiring molecularlevel understanding of the reaction mechanism. This contribution shows that Ag nanoparticles, displaying metal sizes in the range of 2-20 nm, are intrinsically selective $(>90 \%)$ for the partial hydrogenation of propyne. Certain kinetic fingerprints of $\mathrm{Ag}$, like the positive dependence of the $\mathrm{C}_{3} \mathrm{H}_{4}$ pressure, the relatively low reaction order in $\mathrm{H}_{2}$, and the low apparent activation energy, deviate from conventional metals like $\mathrm{Pd}$ or $\mathrm{Ni}$, and question the applicability of the Horiuti-Polanyi scheme [1]. Density Functional Theory (DFT) calculations and micro-kinetic modeling demonstrate the occurrence of an alternative mechanism, featuring the activation of hydrogen on the adsorbed propyne. This broadens the mechanistic diversity of hydrogenation mechanisms over solid surfaces and opens new directions for understanding other poor $\mathrm{H}_{2}$-splitting metals.
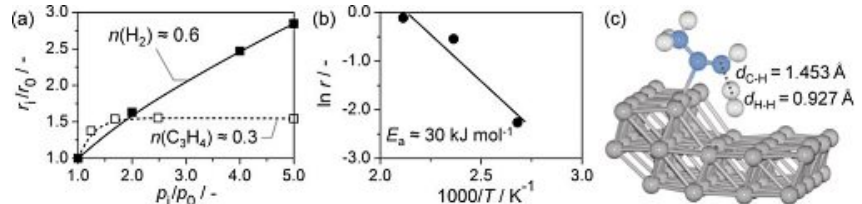

Fig. 1. Orders of reactions (a), Arrhenius plot (b), and transition state for $\mathrm{H}_{2}$ activation via the proposed hydrogenation mechanism (c).

[1] J. Horiuti, M. Polanyi, Trans. Faraday Soc. 1934, 30, 1164.
Catalysis Science Engineering

CSE30

\section{Binder design in technical zeolite catalysts for methanol to olefins}

Nina-Luisa Michels, Sharon Mitchell, Maria Milina, Javier Pérez-Ramírez*

\section{ETH Zurich, Wolfgang-Pauli-Strasse 10, CH-8093 Zurich, Switzerland}

Industrially, most heterogeneous catalysts are applied in the form of shaped bodies to permit facile handling and recovery, and to avoid pressure drops. These technical catalysts differ strongly from their research analogues, i.e. a single bulk/supported active phase in powder form, as binders must be incorporated to enhance the mechanical stability. Interactions between the binder and the active phase cause compositional changes, alter the mass transfer within shaped zeolite bodies, and ultimately affect the catalytic performance. This work aims to understand synthesis-property-function relationships with respect to the chosen binder properties in order to improve technical zeolite design (Fig. 1) in the conversion of methanol to olefins.
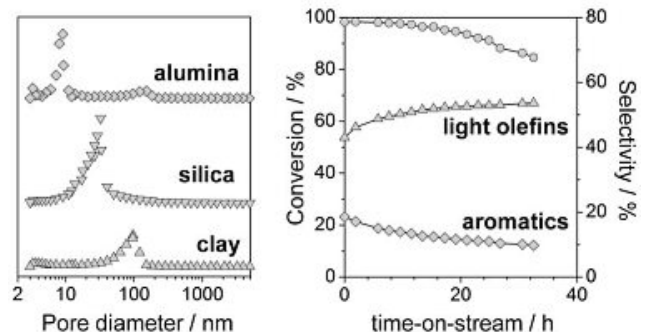

Fig. 1. Rationalizing the performance of binder-containing zeolite catalysts in the conversion of methanol to olefins

[1] S. Mitchell, N.-L. Michels, K. Kunze, J. Pérez-Ramírez, Nature Chem. 2012, 4, 825

[2] L. Gueudré, M. Milina, S. Mitchell, J. Pérez-Ramírez, Adv. Funct. Mater. 2013, DOI: 10.1002/adfm.201203557.

New insights into the promotion of methanol synthesis catalysts by $\mathrm{CO}_{2}$

Oliver Martin $^{1}$, Charlotte Drouilly ${ }^{2}$, Stefanie Kohler ${ }^{2}$, Daniel Curulla-Ferré ${ }^{2}$, Javier Pérez-Ramírez ${ }^{1, *}$

${ }^{1}$ ETH Zurich, Wolfgang-Pauli-Strasse 10, CH-8093 Zurich, Switzerland ${ }^{2}$ Total Research \& Technology Feluy, Zone Industrielle Feluy C, B-7181 Seneffe, Belgium

Methanol is a high demand chemical expected to become even more important in a post-oil society. Interestingly, $\mathrm{CO}_{2}$ highly enhances the synthesis of methanol from syngas $\left(\mathrm{CO} / \mathrm{H}_{2}\right)$ over $\mathrm{Cu}-\mathrm{ZnO}-\mathrm{Al}_{2} \mathrm{O}_{3}$ [1]. However, there is still a lack of understanding the reasons for this phenomenon and its connection to the catalyst composition. We demonstrate that consecutively altering the $\mathrm{CO}_{2}$ concentration in the syngas feed without removing the catalyst from the reactor provides improved insight into the promotional effect over catalysts of varied compositions: a strong synergism between $\mathrm{Cu}$ and $\mathrm{ZnO}$ is found, which depends strongly on the gas feed composition and the catalyst history (Fig. 1). Consequently, the surface composition and the oxidation state of $\mathrm{Cu}$ surface sites appear to determine the catalytic performance of methanol synthesis catalysts beside the particle size dependence of the reaction.
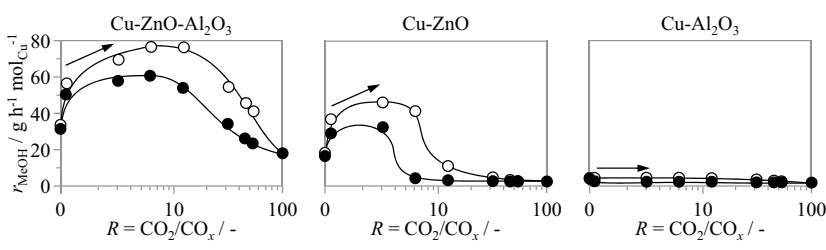

Fig. 1. Methanol synthesis at $513 \mathrm{~K}, 5.0 \mathrm{MPa}$, and $\mathrm{H}_{2}: \mathrm{CO}_{\mathrm{x}}=7\left(\mathrm{CO}_{\mathrm{x}}=\mathrm{CO}+\mathrm{CO}_{2}\right)$ over $\mathrm{Cu}$-based catalyst compositions keeping the atomic ratio constant at $\mathrm{Cu}: \mathrm{Zn}: \mathrm{Al}$ $=6: 3: 1 . \mathrm{ZnO}-\mathrm{Al}_{2} \mathrm{O}_{3}$ possesses only poor activity $(\mathrm{X}<0.1 \%)$ and no hysteresis.

[1] K. Klier, Adv. Catal. 1982, 31, 243.

\section{Rational design of novel sorbents for $\mathrm{CO}_{2}$ capture}

Markus Hammes, Oliver Martin, Javier Pérez-Ramírez

ETH Zurich, Wolfgang-Pauli-Strasse 10, CH-8093 Zurich, Switzerland

Deriving from the ability to incorporate $\mathrm{CO}_{2}$ reversibly [1], dawsonite-based materials have been reported as candidates for capturing $\mathrm{CO}_{2}$ from point sources [2]. The sorption capacity of these materials is enriched by the presence of $\mathrm{H}_{2} \mathrm{O}$ vapor, which is inherent in coal-derived flue gases. Such benefit distinguishes dawsonites from other materials which are unstable under humid conditions. Therefore, we have monitored the reversible carbonation of dawsonite powders revealing a $\mathrm{CO}_{2}$ uptake of $\sim 1.4 \mathrm{mmol} \mathrm{g}^{-1}$ over five cycles (Fig. 1a,b). Consequently, we have been studying dawsonites in shaped bodies in order to highlight the potential implementation in industrial capture units. Our scope is to rationally engineer extrudates, being mechanically and thermally stable towards a broad range of conditions, i.e. humidified gases, elevated pressures and medium temperatures. Equally structural parameters will correlate to the sorption performance. (a)

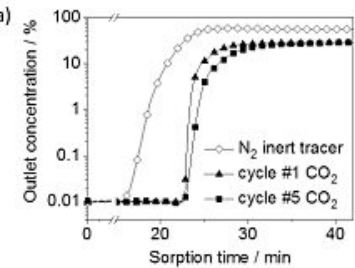

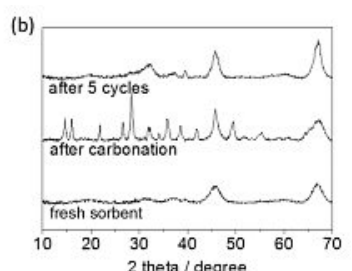

Fig. 1. (a) $\mathrm{CO}_{2}$ breakthrough curves in cycle 1 and 5 over a dawsonite sample at $473 \mathrm{~K}$ $3 \mathrm{MPa}, \mathrm{CO}_{2}: \mathrm{H}_{2} \mathrm{O}=1: 1 \mathrm{~N}_{2}$-balanced. (b) PXRDs of calcined dawsonite sample (bottom), after carbonation (middle) and after 5 cycles (top).

[1] G. Stoica, J.C. Groen, S. Abelló, R. Manchanda, J. Pérez-Ramírez, Chem. Mater. 2008, 20, 3973.

[2] S. Walspurger, P.D. Cobden, W.G. Haije, R. Westerwaal, G.D. Elzinga O.V. Safonova, Eur. J. Inorg. Chem. 2010, 2461-2464. 
Catalysis Science Engineering

CSE33

\section{Hydrolytic hydrogenation of hemicelluloses over Ru modified} hierarchical zeolites

Bright T. Kusema ${ }^{1}$, Pierre Y. Dapsens ${ }^{1}$, Elena V. Murzina ${ }^{2}$, Anton Tokarev ${ }^{2}$, Kalle Arve ${ }^{2}$, Cecilia Mondelli ${ }^{1}$, Dmitry Yu. Murzin ${ }^{2}$, Javier Pérez-Ramírez ${ }^{1,}$

${ }^{1}$ ETH Zurich, Wolfgang-Pauli-Strasse 10, CH-8093 Zurich, Switzerland

${ }^{2}$ Åbo Akademi University, Biskopsgatan 8, FI-20540 Åbo, Finland

The concept of an integrated biorefinery system involves the catalytic transformation of bio-based feedstocks into chemicals, materials, and fuels Hemicelluloses such as xylan and arabinogalactan account for $20-35 \%$ of lignocellulosic biomass. Novel bi-functional catalytic strategies have been advanced for the simple, one-pot transformation of hemicelluloses to produce value-added chemicals [1]. Hierarchical zeolites are solid acid catalysts which integrate mesoporosity with their inherent microporosity enhancing their catalytic effectiveness. We show that Ru-modified hierarchical USY and beta zeolites displayed higher activity for the hydrolysis of hemicellulose than conventional zeolites due to improved accessibility of the acid sites. Besides, the selectivity to polyols was further enhanced by facilitated product diffusion.

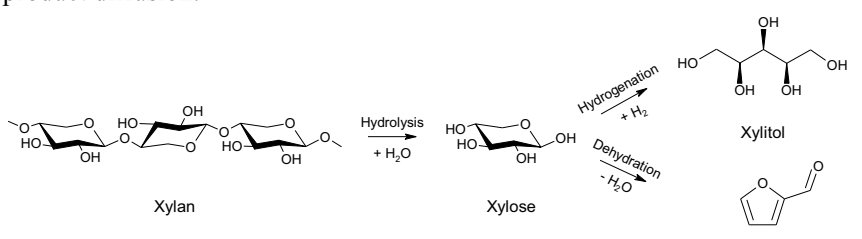

Furfural

Fig. 1. Reaction scheme of the one-pot hydrolytic hydrogenation of xylan into xylose, xylitol and furfural over Ru modified hierarchical zeolites.

[1] B. T. Kusema, L. Faba, N. Kumar, P. Mäki-Arvela, E. Díaz, S. Ordóñez, T. Salmi, D. Yu. Murzin, Catal. Today 2012, 196, 26.
Catalysis Science Engineering

CSE34

\section{Catalytic Upgrading of Pyrolysis Oil: Vapor Phase Self-Condensation of Aldehydes}

\section{Elodie G. Rodrigues, Tobias C. Keller, Javier Pérez-Ramírez}

ETH Zurich, Wolfgang-Pauli-Strasse 10, CH-8093 Zurich, Switzerland

Bio-oil obtained through fast pyrolysis of lignocellulosic biomass represents a promising pathway for the production of renewable fuels. However, in order to meet requirements in terms of heating value and stability, a subsequent upgrading step is required, usually aiming the removal of oxygen in form of water from the mixture.[1] As energy efficiency is key in this upgrading step, catalytic refinement through acid- and base-catalyzed condensation reactions over zeolite-based catalysts could yield the solution, a good understanding of the complex reaction network is however essential.

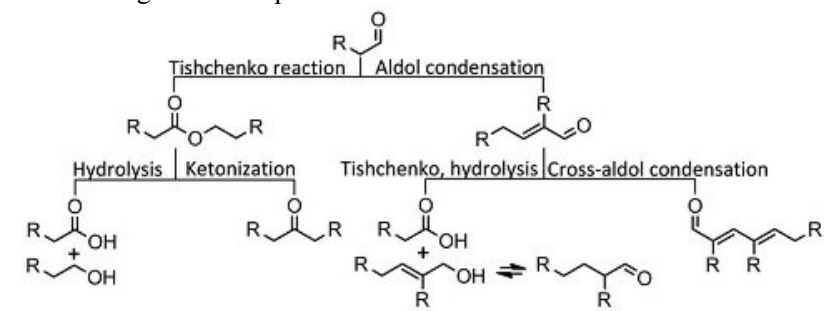

Fig. 1. Reaction network for the catalytic conversion of aldehydes.

In order to decouple the complex interplay between acidity, basicity, and porosity in the different reaction pathways, hierarchical zeolites and zeolite nanocomposites with distinct acid-base properties were prepared and tested in vapor phase condensations of linear aldehydes. From the thereby obtained insights, promising bio-oil upgrading catalysts were identified and design criteria defined.

[1] Michael Stöcker, Angew. Chem., Int. Ed. 2008, 47, 9200-9211.
Porosity-acidity interplay in hierarchical zeolites and relevance for the design of improved liquid-phase alkylation and esterification catalysts

Maria Milina $^{1}$, Sharon Mitchell $^{1}$, Jeffrey Kenvin $^{2}$, Javier Pérez-Ramírez $^{1, *}$

${ }^{1}$ ETH Zurich, Wolfgang-Pauli-Strasse 10, CH-8093 Zurich, Switzerland

${ }^{2}$ Micromeritics, Communications Dr. 4356, 30093 Norcross, GA, USA

Hierarchical ZSM-5 zeolites with intracrystalline mesopores can be effectively prepared by desilication, while simultaneously modifying the bulk composition and acidity [1]. Effects of the latter are frequently overlooked due to a general dominance of porosity in diffusion-limited processes. Herein, advanced spectroscopic, temperature-programmed, and catalytic techniques are applied to characterize distinct acidic properties and the results are correlated with the porosity and compositional variations. The catalytic implications are evaluated in liquid-phase alkylation and esterification reactions. Analysis of the activity and selectivity relative to the distinct transport and acidity demands, enable identification of key parameters in the postsynthetic design.
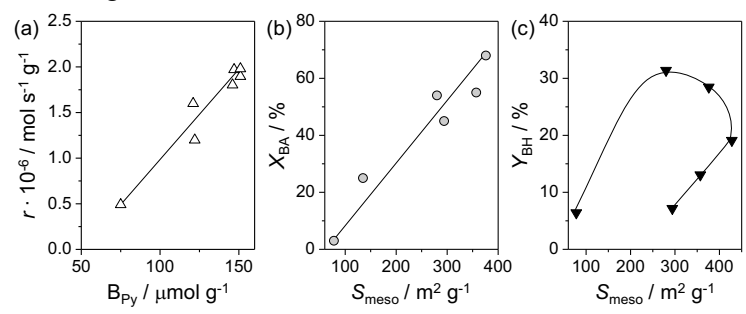

Fig. 1. Catalytic activity of the zeolites in (a) cracking of n-hexane, (b) alkylation of toluene, and (c) esterification of benzyl alcohol, with respect to key properties.

[1] M. Milina, S. Mitchell, Z. Domíngues Trinidad, D. Verboekend, J. Pérez-Ramírez, Catal. Sci. Technol. 2012, 2, 759.

\section{Tailored hierarchical zeolite catalysts for the isomerization of bio- derived substrates}

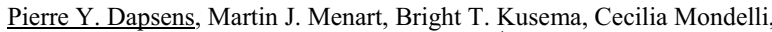
Javier Pérez-Ramírez ${ }^{*}$

ETH Zurich, Wolfgang-Pauli-Strasse 10, CH-8093 Zurich, Switzerland

The production of chemicals through the catalytic conversion of biomass is receiving considerable interest. Particularly, lactic acid (LA) and alkyl lactates can be attained by the heterogeneous Lewis acid-catalyzed isomerization of dihydroxyacetone (DHA) (Fig. 1, center). Nevertheless, this transformation still lacks industrially applicable catalysts. Herein, we show that performing catalysts can be obtained using affordable and scalable postsynthetic treatments of commercial zeolites (e.g. MFI and FAU) [1]. While simple alkaline treatment of MFI generates tetra-coordinated Lewis acid centers highly selective for the production of LA, the presence of a gallium salt in the alkaline media enables to further tune the amount and the nature of these Lewis sites as exemplified with the production of ethyl lactate (EL) over modified FAU-type zeolites (Fig. 1). Selectivity to LA and EL of $92 \%$ were obtained over our best catalysts, comparable to that of the state-of-theart catalyst (Sn-beta). The materials are fully reusable several times.
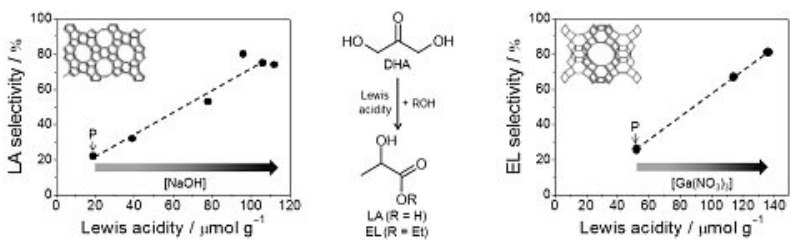

Fig. 1. Lewis acidity (probed by IR of adsorbed pyridine) versus the selectivity to $L A$ and $E L$ over parent $(P)$ and post-synthetic treated zeolites.

[1] P.Y. Dapsens, C. Mondelli, J. Pérez-Ramírez, ACS Catal. 2012, 2, 1487 
Catalysis Science Engineering

CSE37

Catalytic bromine recovery - an enabling technology for new alkane functionalization processes

Maximilian Moser, Laura Rodríguez García, Amol P. Amrute, Javier Pérez-Ramírez

ETH Zurich, Wolfgang-Pauli-Strasse 10, CH-8093 Zurich, Switzerland

Bromine-mediated upgrading of alkanes to commodity chemicals (i.e. olefins, alcohols, and liquid hydrocarbons) is a novel and efficient alternative to conventional (steam) cracking and dehydrogenation [1]. However, the success of this technology strongly depends on the recycling of the large amounts of $\mathrm{HBr}$ by-product. Consequently, their implementation is tightly linked to the development of a robust technology for bromine recovery. The catalyzed gas-phase oxidation of $\mathrm{HBr}$ to bromine is a smart and energy-efficient route (compared to electrolysis) to close the "bromine cycle" (Fig. 1). The application of $\mathrm{HCl}$ oxidation catalysts is in principle feasible, but no experimental study has been undertaken yet [2]. Herein, we present fundamental understanding on activity, stability and mechanism of $\mathrm{HBr}$ oxidation over shaped Deacon catalysts $\left(\mathrm{RuO}_{2}, \mathrm{CeO}_{2}\right.$, $\mathrm{IrO}_{2}$, and $\mathrm{CuO}$-based), and draw comparisons to the well-described $\mathrm{HCl}$ oxidation. Further, we analyze the feasability of implementation of the catalytic $\mathrm{HBr}$ oxidation at industrial scale by conceptual reactor simulations.

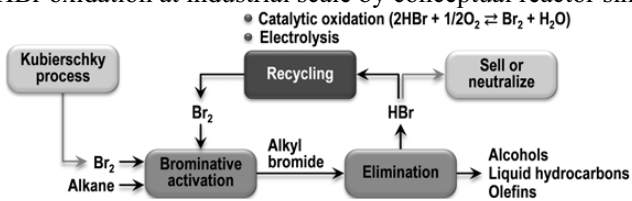

Fig 1. Efficient upgrading of alkanes to valuable commodity chemicals via brominative activation followed by elimination with an integrated bromine recovery process.

[1] E. McFarland, Science 2012, 338, 340.

[2] A. Toftelund, I. C. Man, H. A. Hansen, F. Abild-Pedersen, T. Bligaard, J. Rossmeisl, F. Studt, ChemCatChem 2012, 11, 1856.
Catalysis Science Engineering

CSE38

In situ XAS of $\mathrm{CeO}_{2}$-based materials for two-step solar thermochemical $\mathrm{H}_{2} \mathrm{O}$ and $\mathrm{CO}_{2}$ splitting

Matthäus Rothensteiner ${ }^{1}$, Hermann Emerich $^{2}$ and Jeroen Anton van Bokhoven $^{1}$

${ }^{1}$ ETH Zurich/Paul Scherrer Institut, 5232 Villigen PSI, Switzerland ${ }^{2}$ European Synchrotron Radiation Facility, 6 Rue Jules Horowitz BP 220 , 38043 Grenoble Cedex 9, France

Thermochemical cycles driven by concentrated solar radiation as source of high temperature heat are promising processes for the energy efficient and sustainable generation of fuels. Oxygen storage materials such as ceria-based nonstoichiometric oxides are of great interest as reactive intermediates for the production of $\mathrm{H}_{2}$ from $\mathrm{H}_{2} \mathrm{O}$ (and $\mathrm{CO}$ from $\mathrm{CO}_{2}$ ) in a two-step redox cycle [1] Typical process temperatures are $1773 \mathrm{~K}$ for the reduction step (1) and 1273 $\mathrm{K}$ for the oxidation step (2)

$$
\begin{gathered}
\mathrm{CeO}_{2-\delta_{1}} \stackrel{1773 K}{\longrightarrow} \mathrm{CeO}_{2-\delta_{2}}+\frac{\delta}{2} \mathrm{O}_{2} \\
\mathrm{CeO}_{2-\delta_{2}}+\delta \mathrm{H}_{2} \mathrm{O} \stackrel{1273 K}{\longrightarrow} \mathrm{CeO}_{2-\delta_{1}}+\delta \mathrm{H}_{2}
\end{gathered}
$$

The introduction of dopants strongly affects the non-stoichiometry $\delta_{i}$, which is pivotal for the efficiency of the process. However, little is known about the structural changes that occur under these conditions and the effects of introducing dopants are poorly understood. In situ XAFS measurements at the $\mathrm{Ce} \mathrm{K}$ edge are used to determine the electronic structure of $\mathrm{Ce}\left(\mathrm{Ce}^{\mathrm{III}} / \mathrm{Ce}^{\mathrm{IV}}\right.$. ratio) and local geometric distortions of the fluorite-type $\mathrm{CeO}_{2-\delta}$ lattice under relevant conditions up to $1773 \mathrm{~K}$. In the light of these extreme conditions, we explore the temperature range in which useful in situ spectroscopic data can be obtained to identify oxygen vacancies and establish relationships between the structure of the material and its properties such as oxygen storage capacity, reaction kinetics and stability.

[1] Chueh W.C., Falter C., Abbott M., Scipio D., Furler P., Haile S.M., Steinfeld, A. Science 2010, 330 1797-801.
Formation of particles under reaction conditions for methane steam reforming

Renata B. Duarte, ${ }^{\mathrm{a}}$ Jeroen A. van Bokhoven ${ }^{\mathrm{a}, \mathrm{b}}$

${ }^{\mathrm{a}}$ ETH Zurich, Institute for Chemical and Bioengineering, 8093 Zurich, Switzerland

${ }^{\mathrm{b}}$ Paul Scherrer Institute, 5232 Villigen PSI, Switzerland

The recent discovery of active single site catalysts on heterogeneous supports [1] has received considerable attention. The MSR reaction is important to obtain $\mathrm{H}_{2}$ and $\mathrm{Rh}$ is one of the most active metals for this reaction. We have synthesized $\mathrm{Rh}$ catalysts on $\mathrm{Al}_{2} \mathrm{O}_{3}$ and $x \mathrm{Sm}_{2} \mathrm{O}_{3}-y \mathrm{CeO}_{2}-\mathrm{Al}_{2} \mathrm{O}_{3}$ with atomically dispersed Rh (Figure 1) and analyzed their catalytic performance. $\mathrm{Rh} / \mathrm{Al}_{2} \mathrm{O}_{3}$ showed stronger deactivation during reaction due to sintering. $\mathrm{Rh} / 12 \mathrm{CeO}_{2}-\mathrm{Al}_{2} \mathrm{O}_{3}$ showed best performance due to the partial stability of the active phase dispersion. The addition of both promoters led to the inhibition of $\mathrm{Rh}$ sintering and lowered reaction rates. The co-existence of small clusters and single atoms complement each other for the execution of the many steps in MSR, which include bond breaking and formation. Based on the STEM images, it can be concluded that Rh sinters with time on stream.
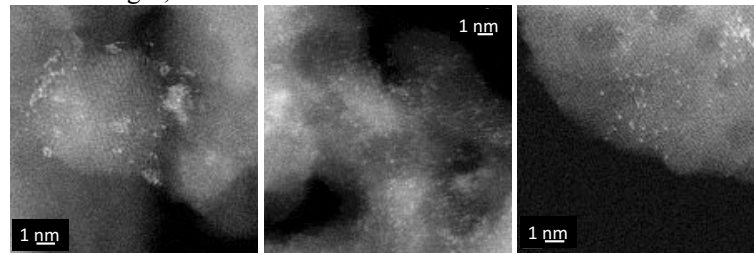

Figure 1. HAADF-STEM micrographs of $\mathrm{Rh} / \mathrm{Al}_{2} \mathrm{O}_{3}$ (left), $\mathrm{Rh} / 12 \mathrm{CeO}_{2}$ $\mathrm{Al}_{2} \mathrm{O}_{3}$ (middle) and $\mathrm{Rh} / 6 \mathrm{Sm}_{2} \mathrm{O}_{3}-6 \mathrm{CeO}_{2}-\mathrm{Al}_{2} \mathrm{O}_{3}$ (right) catalysts after calcination at $773 \mathrm{~K}$. Rhodium appears as bright spots ( $\mathrm{Z}$ contrast).

[1] B.T. Qiao, A.Q. Wang, X.F. Yang, L.F. Allard, Z. Jiang, Y.T. Cui, J.Y. Liu, J. Li, T. Zhang, Nat Chem. 2011, 3, 634.
Photocatalytic Water Oxidation with Polyoxometalates and Cubanes

\section{F. Evangelisti, K. von Allmen, P.-E. Car, R. Moré, R. Guettinger G. R. Patzke*}

Institute of Inorganic Chemistry, University of Zurich, Winterthurerstrasse 190, CH-8057 Zurich, Switzerland

Visible light driven water oxidation is a key step of artificial photosynthesis as an attractive option to directly convert light into storable fuels. Catalytic activity for water oxidation was observed for polyoxometalates (POMs) containing $\mathrm{Ru}$ and $\mathrm{Co}$ atoms in the transition metal belt. $\mathrm{Na}_{6} \mathrm{~K}\{\alpha$ $\mathrm{SiW}_{9} \mathrm{O}_{37} \mathrm{Ru}_{3}\left(\mathrm{H}_{2} \mathrm{O}\right) \mathrm{Cl}_{2}$ \} was recently reported as a promising water oxidation catalyst (WOC) in a system containing $\mathrm{Ru}(\mathrm{bpy})_{3}{ }^{2+}$ as a photosensitizer ${ }^{[1]}$ Various cobalt-based POMs were recently identified as WOCs. ${ }^{[2]}$ We furthermore found a new cobalt containing bismuth tungstate to be active as WOC, while its manganese containing structural analogue is inactive. Electrochemical investigations indicate that this may be due to the low redox potential of the Mn-POM.

Cobalt containing cubanes are another excellent WOC class. Modification of the classic cubane structures by incorporating lanthanide ions allows to modify the catalytic activity. EXAFS measurements on the Co K-edge were performed to obtain further insight into stability and mechanisms of such molecular WOCs through in situ monitoring of changes in the Co coordination sphere. Additionally, XANES spectra provide information on the oxidation states of the catalytic centers. ${ }^{[3]}$

[1] P.-E. Car, M. Guttentag, K. K. Baldridge, R. Alberto, G. R. Patzke, Green Chem. 2012, 14, 1680 .

[2] Q. Yin, J. M. Tan, C. Besson,Y. V. Geletii, D. G. Musaev, A.E. Kuznetsov, Z. Luo, K. Hardcastle, C. L. Hill, Science 2010, 328, 34.

[3] M. Martis, K. Mori, K. Kato, G. Sankar, H. Yamashita, ChemPhysChem 2013, DOI: 1002/cphc.201201093. 
Catalysis Science and Engineering

CSE41

\author{
A synchronous XAS/DRIFTS/MS setup for time-resolved structure- \\ activity measurements \\ Gian Luca Chiarello ${ }^{1,2}$, Valentina Marchionni ${ }^{1,3}$, Maarten Naachtegal ${ }^{3}$, \\ Davide Ferri ${ }^{1,3}$
}

${ }^{1}$ Empa, Lab. for Solid State Chemistry and Catalysis, CH-8600 Dübendorf, Switzerland; ${ }^{2}$ Università degli Studi di Milano, I-20133 Milano, Italy; ${ }^{3}$ Paul Scherrer Institute, CH-5232 Villigen, Switzerland

A spectroscopic cell for synchronous XAS/DRIFTS/MS measurements has been designed and commissioned at the SuperXAS beamline of the Swiss Light Source. The further combination with a modulated excitation (ME) approach allows significant sensitivity enhancement of these time-resolved techniques [1]. The new cell simulates a plug-flow reactor, offers a wide surface for IR collection and a variable thin sample thickness for transmission X-ray absorption spectroscopy (XAS) of highly absorbing materials. The ME approach is facilitated by the absence of dead volume around the sample. First measurements were performed on $\mathrm{Pt} / \mathrm{Al}_{2} \mathrm{O}_{3}$ using alternated $\mathrm{CO} / \mathrm{O}_{2}$ pulses. Time-resolved XAS spectra at the $\mathrm{Pt} \mathrm{L}_{\mathrm{III}}$-edge exhibited a regular variation of the whiteline intensity in response to repeated $\mathrm{CO}\left(\right.$ or $\mathrm{H}_{2}$ ) and $\mathrm{O}_{2}$ pulses. The structural changes were greatly enhanced after phase sensitive analysis of the time-resolved data [1]. The data quality allows for detailed XAS analysis and the identification of Pt$\mathrm{CO}$ and Pt-H species in the phase-resolved spectra. The corresponding DRIFT spectra exhibited the characteristic signals of adsorbed $\mathrm{CO}$ on $\mathrm{Pt}^{0}$ in linear $\left(\mathrm{CO}_{\mathrm{L}}\right)$ and bridged geometry. The corresponding phase-resolved spectra revealed the existence of two $\mathrm{CO}_{\mathrm{L}}$ species exhibiting different response to the $\mathrm{CO} / \mathrm{O}_{2}$ modulation. These preliminary data show that the unique combination of time-resolved bulk sensitive XAS and surface sensitive DRIFTS is possible in the new cell and that the sensitivity of the two techniques is greatly enhanced by the ME approach.

[1] D. Baurecht et al., Rev. Sci. Instr. 2001, 72, 3782; D. Ferri et al., PCCP, 2010, 12, 5634; C. König et al., J. Phys. Chem. C, 2012, 116, 19857.
Catalysis Science Engineering

CSE42

\section{Ageing induced three-way catalytic activity improvement of hexagonal $\mathrm{Pd} / \mathrm{YFeO}_{3}$}

$\underline{\text { Ye Lu}^{1}}$, Sylvain Keav ${ }^{1}$, Alexandra E. Maegli ${ }^{1}$, Santhosh K. Matam ${ }^{1}$, Anke Weidenkaff $^{1}$, Davide Ferri ${ }^{2}$

${ }^{1}$ Empa, Lab. for Solid State Chemistry and Catalysis, Ueberlandstrasse 129, CH-8600 Dübendorf, Switzerland

${ }^{2}$ Paul Scherrer Institute, CH-5232 Villigen, Switzerland

'Self-regenerative' perovskite-type oxides are promising candidates as threeway catalysts in the after treatment of stoichiometric engines [1]. Sintering and stabilization of the noble metal nano-particles can be achieved under high temperature reaction conditions and prolonged operation. Recently, hexagonal $\mathrm{YFeO}_{3 \pm \delta}$ was also reported as potential support of Pd with similar properties [2].

Hexagonal $\mathrm{YFeO}_{3}$ supported Pd samples with $0.5 \mathrm{wt} \%$ and $2 \mathrm{wt} \% \mathrm{Pd}$ content prepared by the flame spray synthesis (FSS) exhibited significant dispersion of the active $\mathrm{Pd}$ phase and displayed $\mathrm{T}_{50 \%}$ for $\mathrm{CH}_{4}$ oxidation under stoichiometric conditions $\left(\lambda=1 ; \mathrm{CO}, \mathrm{CH}_{4}, \mathrm{NO}, \mathrm{O}_{2}\right)$ of ca. $723 \mathrm{~K}$ in contrast to the $600 \mathrm{~K}$ of the reference $\mathrm{Pd} / \mathrm{ACZ}$ catalyst. The catalysts were then aged under thermal (air) and stoichiometric conditions at $1173 \mathrm{~K}$ for $2 \mathrm{~h}$. Both ageing processes caused the severe loss of surface area of the two $\mathrm{YFeO}_{3}$ based catalysts because of $\mathrm{YFeO}_{3}$ particle sintering. However, the sintering of Pd particles appeared limited. In contrast to the thermally aged catalyst, XPS and HAADF-STEM revealed metallic Pd nano-particles of 10-20 nm in diameter after stoichiometric ageing. Remarkably, the light-off temperature of $\mathrm{Pd} / \mathrm{YFeO}_{3}(600 \mathrm{~K})$ was identical to that of $\mathrm{Pd} / \mathrm{ACZ}$ after stoichiometric ageing, thus making flame-made $\mathrm{Pd} / \mathrm{YFeO}_{3}$ an interesting catalyst for the removal of $\mathrm{CH}_{4}$ from vehicle exhaust.

[1] Y. Nishihata, et al., Nature, 2002, 418, 164.

[2] J. Li, et al., Chem. Mater., 2008, 20, 6567; A. Eyssler, et al., Chem. Mater., 2012, 24, 1864.
Expanding the series of phosphine-substituted metal-organic frameworks: towards a suitable platform for heterogeneous hydrogenation

Flavien L. Morel, ${ }^{1,2}$ Marco Ranocchiari, ${ }^{1 *}$ Jeroen A. van Bokhoven ${ }^{1,2^{*}}$

${ }^{1}$ Paul Scherrer Institut, Laboratory for Catalysis and Sustainable Chemistry, CH-5232 Villigen, Switzerland

${ }^{2}$ ETH Zurich, Wolfgang-Pauli Str. 10, CH-8039 Zurich, Switzerland

Metal-organic frameworks (MOFs) are a porous, crystalline class of coordination polymers, whose development in the past decade is leading to exciting applications in catalysis. [1] Phosphine-substituted metal-organic frameworks (P-MOFs) are a subclass of MOFs, recently investigated as possible acceptors for metal catalysis.

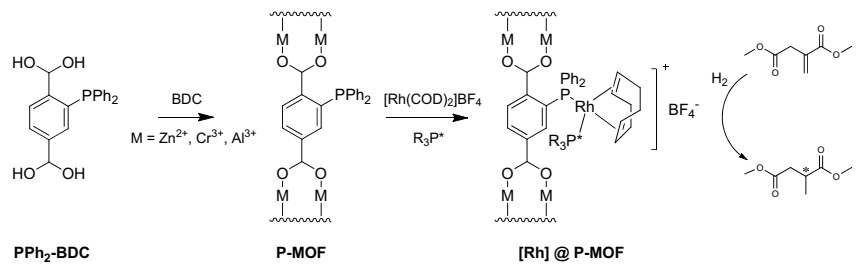

We present here our recent development in the synthesis of the phosphinoterephtalic acid ligand $\left(\mathrm{PPh}_{2}-\mathrm{BDC}\right)$, a key ligand towards $\mathrm{P}-\mathrm{MOF}$ based on highly stable frameworks such as MIL-101. [2] The relevance of the synthesized P-MOFs to catalysis will be illustrated using the ability of the phosphine moieties to bind rhodium complexes, which are used as precursors for asymmetric hydrogenation of alkenes.

[1] M. Ranocchiari, J. van Bokhoven, Phys. Chem. Chem. Phys. 2011, 13, 6388-96.

[2] G. Férey C. Mello-Draznieks et al., Science, 2005, 309, 2040-2.
Product Analysis to Study the Mechanism of the Electrochemical Reduction of $\mathrm{CO}_{2}$

Jorge V.F. Araújo $^{\mathrm{a}}$, M. Özaslan ${ }^{\mathrm{a}}$, P. Rodriguez ${ }^{\mathrm{b}}$, R. Kötz ${ }^{\mathrm{a}}$, T. J. Schmidt ${ }^{\mathrm{a}^{*}}$ ${ }^{a}$, Electrochemistry Laboratory, Paul Scherrer Institut, PSI Villigen, 5232, Switzerland.

b, School of Chemistry, University of Birmingham, Edgbaston, Birmingham, B15 2TT, United Kingdom.

The electrochemical reduction of $\mathrm{CO}_{2}$ is a promising process to efficiently convert $\mathrm{CO}_{2}$ into energetically useable molecules, e.g., fuels. The capture and storage of $\mathrm{CO}_{2}$ waste in power plants has emerged as a technically feasible process with proper re-conversions possibilities into fuel still being missing. Copper is known to be a unique electrocatalyst for $\mathrm{CO}_{2}$ reduction to produce a variety of products such as hydrocarbons ${ }^{1}$. It has been reported that the product distribution and the activation energy for $\mathrm{CO}_{2}$ reduction strongly depends on the crystallographic orientation of $\mathrm{Cu}$ as well as the formation of intermediates ${ }^{2}$. The goal of our investigation is to identify the effects of the geometric and electronic structure of copper electrodes on the $\mathrm{CO}_{2}$ reduction reaction. Therefore, we used a combination of two complementary techniques to better understand the atomic processes for $\mathrm{CO}_{2}$ electroreduction: Differential Electrochemical Mass Spectrometry (DEMS) and Infrared Spectroscopy (FTIR) are employed to monitor in-situ the analysis of gaseous product distribution and intermediate species as a function of the applied potential.

First results of these two techniques (DEMS and in situ FTIR) for the product analysis on $\mathrm{Cu}$ during the $\mathrm{CO}_{2}$ reduction will be presented.

[1] M. Gattrell, N. Gupta and A. Co, J. Electroanal. Chem., 2006, 594, 1-19.

[2] Y. Hori in Modern Aspects of Electrochemistry, C. Vayenas et al., Springer, 2008, 42, 89-189. 
Catalysis Science Engineering

\section{Isotopic frequency response for heterogeneous catalysis}

$$
\underline{\text { Urs Hartfelder }^{1}} \text {, Jeroen A. van Bokhoven }{ }^{1,2}
$$

${ }^{1}$ Institute for Chemical and Bioengineering, ETH Zürich, 8093 Zürich

${ }^{2}$ Laboratory for Catalysis and Sustainable Chemistry, PSI, 5232 Villigen

The rational development of advanced heterogeneous catalysts for the chemical industry, environmental and energy applications requires a mechanistic understanding of catalysis. Conventional spectroscopic and kinetic methods are limited by spectator problems and mechanistic ambiguity. These limitations can be overcome by transient methods, i.e. variation of the reaction conditions with time and monitoring of the adaption of the system to the new conditions. Isotopic labeling, as used for example in the SSITKA method is a particularly useful type of input, because it represents the smallest possible deviation from the true steady state, while the response is still clearly detectable, e.g. by mass spectrometry. In this contribution, we present theoretical considerations for the use of transient isotopic labeling for investigating catalytic reaction kinetics, including different mechanisms ${ }^{1}$. It is shown how mikrokinetic parameters can be derived from the frequency response for these cases. In addition, some general features and similarities of transient methods are discussed.

\section{Feed composition Reactor Shifted output} modulation

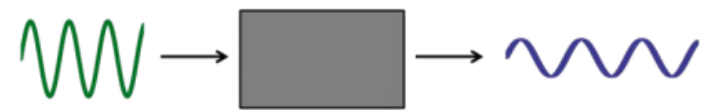

Figure 1: The isotopic composition of the reactor feed is varied with time, resulting in a shifted variation in the product composition. The shift depends on kinetic parameters of the catalyst.

[1] U. Hartfelder, J. Szlachetko, J. Sa, J. A. van Bokhoven, Analyst 2012, 137, 5374-5381.

Catalysis Science Engineering

$\mathrm{MeOH}$ yield modulates with multiple cycles of methane to methanol conversion

Jan Pecháček ${ }^{a, b}$ Evalyn Mae C. Alayon, ${ }^{a, b}$ Marco Ranocchiari, ${ }^{b}$ Jeroen A. van Bokhoven ${ }^{a, b, *}$

${ }^{a}$ Laboratory for Synchotron Radiation - Catalysis and Sustainable Chemistry, Paul Scherrer Institute, 5232 Villigen, Switzerland; ${ }^{b}$ Institute for Chemical and Bioengineering, ETH Zurich, Wolfgang Paulistrasse 10, $8093 \mathrm{Zu}-$ rich, Switzerland (*jeroen.vanbokhoven@chem.ethz.ch)

Copper-exchanged zeolites that were synthesized by aqueous ion exchange of $\mathrm{Cu}^{\mathrm{II}}$-acetate and the $\mathrm{Na}$ - form of the zeolite have been shown to convert methane to methanol under mild conditions [1]. This has inspired our investigations for a possible upgrade to a true catalytic process. We have shown that interaction with water facilitates desorption of the adsorbed intermediate as $\mathrm{MeOH}$ and opens the process to a catalytic cycle by batch-wise operation [2]. Our X-ray absorption spectroscopy data demonstrated that a $\mathrm{Cu}^{\mathrm{I}}$ species is required to activate molecular oxygen, oxidizing to $\mathrm{Cu}^{\mathrm{II}}$, and that a large fraction of $\mathrm{Cu}^{\text {II }}$ reacts with methane [3]. We impregnated mordenite with $\mathrm{Cu} \mathrm{Cl}$ through solid state ion exchange and found that $\mathrm{CuCl}-\mathrm{MOR}$ also converts methane to methanol. On both $\mathrm{Cu}$-zeolites, multiple cycles of oxygen activation, methane reaction, and $\mathrm{MeOH}$ extraction have shown a similar modulation in the amount of methanol that can be produced versus cycle number. An increasing methanol amount is observed during the first three cycles in both $\mathrm{Cu}^{\mathrm{I}}$ and $\mathrm{Cu}^{\mathrm{II}}$ impregnated materials.

[1] M.H. Groothaert, P.J. Smeets, B.F. Sels, P.A. Jacobs, R.A. Schoonheydt, J. Am. Chem. Soc. 2005, 127, 1394.

[2] E.M.C.Alayon, M. Nachtegaal, M. Ranocchiari, J.A. van Bokhoven, Chem. Commun. 2012, 48, 404.

[3] E.M.C. Alayon, M. Nachtegaal, E. Kleymenov, J.A. van Bokhoven, Microporous Mesoporous Mater. 2013, 166, 131
Catalysis Science Engineering

CSE46

\section{Modulated excitation spectroscopic study of hydrothermally-aged $\mathrm{Rh} / \mathrm{Al}_{2} \mathrm{O}_{3}$ for $\mathrm{NO}$ reduction by $\mathrm{CO}$}

\author{
Valentina Marchionni ${ }^{1,3}$, Mark A. Newton ${ }^{2}$, Davide Ferri ${ }^{3}$
}

${ }^{1}$ Empa, Lab. for Solid State Chemistry and Catalysis, CH-8600, Dübendorf, Switzerland; ${ }^{2}$ European Synchrotron Radiation Facility, F-38043 Grenoble, France; ${ }^{3}$ Paul Scherrer Institute, CH-5232 Villigen PSI, Switzerland

The thermal stability of Rh-based catalysts for automotive applications is crucial for $\mathrm{NO}_{\mathrm{X}}$ emission control. Exposure of $\mathrm{Rh} / \mathrm{Al}_{2} \mathrm{O}_{3}$ to high temperatures under lean conditions causes the loss of active metal area by dissolution of Rh in the bulk of the support [1]. This was confirmed by the conventional characterization (BET, CO chemisorption, XRD, TEM) of fresh and hydrothermally aged $2 \mathrm{wt} \% \mathrm{Rh} / \mathrm{Al}_{2} \mathrm{O}_{3}$. The metal dispersion of the aged catalyst decreased to $0.7 \%$ but Rh nano-particles were not visible by TEM, even though the catalyst still exhibited high three-way catalytic activity.

The nature of the species responsible for the activity of the aged catalyst was investigated by the combination of diffuse reflectance infrared spectroscopy (DRIFTS) and X-ray absorption spectroscopy (XAS) with phasesensitive detection (PSD) to enhance their sensitivity towards structural changes [2]. Phase-resolved XANES data demonstrated that ca. $2 \%$ of Rh was still subject to reduction by $\mathrm{CO}$ and oxidation by $\mathrm{NO}$ in the catalyst aged at $1273 \mathrm{~K}$. Therefore, this fraction is likely responsible for the observed catalytic activity. DRIFTS showed that gem-dicarbonyls and linearly adsorbed CO species are sensitive to the red-ox oscillations of the experiments in the aged and the fresh catalysts, respectively. All the catalysts exhibited higher activity at the $\mathrm{NO} \rightarrow \mathrm{CO}$ switch indicating that oxidized $\mathrm{Rh}$ species maybe active for NO reduction. Ageing affects the nature of these species. The EXAFS evaluation of the time-resolved data will provide information on the structure of these species.

[1] D. D. Beck et al., J. Catal. 1993, 144, 311.

[2] A. Urakawa et al., Chem. Eng. Sci. 2008, 69, 4902.

Methyltrioxorhenium Supported on High-Surface Area Nb and Ta Pentoxides: Activity in Olefin Metathesis and Characterization of Reaction Intermediates

Alexey Fedorov, Maxence Valla, Christophe Copéret*

ETH Zürich, Laboratory of Inorganic Chemistry, Wolfgang-Pauli-Str. 10, CH-8093, Zürich, Switzerland

Modern chemical industry relies on heterogeneous olefin metathesis technology to manipulate its olefinic feedstock [1]. It has been known in the literature that rhenium-based niobia catalysts are highly metathesis active, presumably due to high Lewis acidity of the support [2]. However, these supports have typically low surface area, which greatly impact their activity (rate per gram of catalyst).

Here, we have developed high-surface area $\mathrm{Ta}$ and $\mathrm{Nb}$ pentoxides with controlled textural properties and characterized their acidity with probe molecules using ss-NMR and IR techniques. We will also discuss the synthesis and the characterization of the corresponding Re-based alkene metathesis catalysts.

[1] J. C. Mol, J. Mol. Catal. A 2004, 213, 39.

[2] Buffon, R.; Auroux, A.; Lefebvre, F.; Leconte, M.; Choplin, A.; Basset, J.-M.; Herrmann, W. A. J. Mol. Catal. 1992, 76, 287. 
Catalysis Science Engineering

CSE49

\section{C-H bond Hydroxylation Catalyzed by Artificial Metalloenzymes}

\section{K. K. Praneeth and Thomas R. Ward*}

Department of Chemistry, University of Basel Spitalstrasse 51, CH-4056 Basel

The topic of artificial metalloenzymes has fascinated chemists as a means to create hybrid catalysts. These display beneficial properties of both enzymatic- and homogeneous catalytic systems. The biotin-(strept)avidin technology is a powerful non-covalent binding strategy to incorporate biotinylated catalysts to the host protein: either avidin or streptavidin [1]. In a biomimetic spirit, $\mathrm{C}-\mathrm{H}$ hydroxylation using artificial metalloenzymes to selectively functionalize hydrocarbons is an important challenge. We have synthesized different biotinylated complexes bearing tripyridyl methylamine (TPA) ligand as pre-catalysts for $\mathrm{C}-\mathrm{H}$ oxidation reactions. We have investigated the catalytic properties of these biotinlayted complexes in the oxidation of ethylbenzene using $t$ - $\mathrm{BuOOH}$ as oxidant. Both genetic (protein) and chemical (catalyst) optimizations have been performed in order to improve the catalytic efficiency and selectivity. These results together with detailed kinetic studies will be presented.

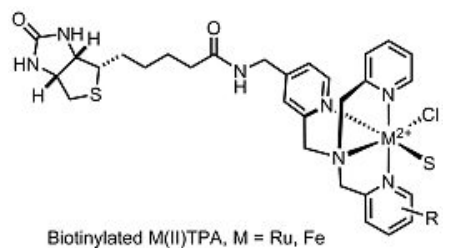

$$
\mathrm{R}=\mathrm{H}, \mathrm{NO}_{2} ; \mathrm{S}=\text { solvent }
$$

[1] T. R. Ward, Acc. Chem. Res. 2011, 44, 47.
Catalysis Science Engineering

CSE50

Where is chromium? Structural and optical study of $\mathrm{TiO}_{2}: \mathrm{Cr}$ flame-made nano-powders towards photocatalytic application.

$\underline{\text { Katarzyna Michalow-Mauke }}{ }^{1,2}$, Eugenio Otal ${ }^{4,5}$, Fabio Lamattina ${ }^{3}$, Karolina Jurkiewicz $^{1,6}$, Davide Ferri ${ }^{1}$, Myriam Aguirre ${ }^{7,8}$, Thomas Graule ${ }^{2}$

${ }^{1}$ Eenergy and Catalysis Lab., Paul Scherrer Institute, CH-5232 Villigen, Switzerland; ${ }^{2}$ Lab. High Performance Ceramics, ${ }^{3}$ Lab. Electronics/ Metrology/Reliability/, Empa Material Science \& Technology, CH-8600

Dübendorf, Switzerland; ${ }^{4}$ UTN-FRSC, Av. Inmigrantes 555, 9400 Rio Gallegos, Argentina; ${ }^{5}$ CITEDEF, San Juan Bautista de La Salle 4397, 1603 Villa Martelli, Argentina; ${ }^{6}$ Faculty of Physics and Applied Computer Science, AGH University of Science and Technology, 30-059 Krakow, Poland; ${ }^{7}$ Inst. Of Nanoscience of Aragón, LMA-Advanced Microscopy Lab., Mariano Esquillor, s/n. E-50018, Zaragoza, Spain; ${ }^{8}$ Dep. de Física de la Materia Condensada, Universidad de Zaragoza, E-50009 Zaragoza, Spain.

A series of $\mathrm{TiO}_{2}: \mathrm{Cr}$ nano-powders with $\mathrm{Cr}$ concentration in the range of $0-20$ at $\%$ were obtained by flame spray synthesis. Cr strongly affected the optical and structural properties of $\mathrm{TiO}_{2}$ : the induced changes were scaling with the increasing $\mathrm{Cr}$ content. Nano-powders were composed of anatase and rutile phase and the increase of the rutile content correlated with the increment of $\mathrm{Cr}$ concentration reaching $90 \mathrm{wt} \%$ for 20 at $\% \mathrm{Cr}$. XAFS revealed that $\mathrm{Cr}$ is in the oxidation state +3 and preferentially located in the rutile structure. The incorporation of $\mathrm{Cr}^{3+}$ in the $\mathrm{TiO}_{2}$ lattice was also confirmed by the photoluminescence study, whereas its preference for rutile by HRTEM/EDX analysis. The presence of $\mathrm{Cr}^{3+}$ in the $\mathrm{Ti}^{4+}$ position causes oxygen vacancy formation as charge compensation, which results in the additional density states within the $\mathrm{TiO}_{2}$ band gap and therefore improves light absorption in the visible range, as was observed by diffuse reflectance spectroscopy. The discussed properties of $\mathrm{TiO}_{2}: \mathrm{Cr}$ demonstrated the substitutional incorporation of $\mathrm{Cr}^{3+}$ into the $\mathrm{TiO}_{2}$ lattice and therefore make the materials promising towards photocatalytic application under visible light irradiation.
Well Defined Nanosized Silver Catalysts for Selective Hydrogenation

Cristina Paun ${ }^{1}$, Jacinto $\mathrm{Sa}^{2}$, Jeroen van Bokhoven ${ }^{2}$

${ }^{1}$ ETH Zurich, Institute of Chemical and Bioengineering, 8093 Zurich, Switzerland

${ }^{2}$ Paul Scherrer Institute, 5232 Villingen, Switzerland

Silver catalysts are effective in selective hydrogenations of the carbonyl group o $\alpha, \beta$-unsaturated aldehydes and nitro group of nitroaromatics due to th oxophilicity of silver. As a consequence, these catalysts show only modest con version for the hydrogenation of olefins. ${ }^{1}$ However, no dedicated study on the influence of shape and size was performed to establish a definite relation between size, surface structure, and reactivity for silver catalysts.

The objective of our study is to understand the relationship between catalyti performance and size/shape of the silver nanoparticles, and in particular the role of exposed surface facets. The strategy is to uncover critical characteristics which define the silver catalysts reactivity. Therefore, we prepared silver NP with controlled exposed facets (nanocubes), supported them on different oxides $\left(\mathrm{Al}_{2} \mathrm{O}_{3}, \mathrm{SiO}_{2}, \mathrm{TiO}_{2}\right)$, and compared the resultant materials with silver impreg. nated on the same supports in the hydrogenation of phenylacetylene. The initia results show that the heterogeneous catalysts have a low activity, but more im. portantly the selectivity to the desired product, styrene, depends on the catalys used, i.e. shaped NPs show better selectivity to styrene compared to impregnated samples.

[1] R. Campostrini, G. Carturan, R.M. Baraka, J. Mol. Catal. 1993, 78, 169.
Operando spectroscopic studies on the origin of phosphorus induced chemical aging of model $\mathrm{Pd}-\mathrm{Al}_{2} \mathrm{O}_{3}$ three-way catalyst

$\underline{\text { Santhosh Kumar Matam }}{ }^{1}$, M. Newton ${ }^{2}$, D. Ferri ${ }^{1}$, C. Bach ${ }^{3}$, A. Weidenkaff ${ }^{1}$

Empa: ${ }^{1}$ Lab. for Solid State Chemistry and Catalysis, ${ }^{3}$ Internal Combustion Engines Lab.; Ueberlandstrasse 129, CH-8600 Dübendorf, Switzerland

${ }^{2}$ European Synchrotron Radiation Facility, F-38043 Grenoble, France

Three-way catalysts (TWC) employed for cleaning automobiles exhaust tend to deactivate due to thermal and chemical aging. The former is the result of high temperature surges and the latter is due to chemical contaminants such as phosphorous $(\mathrm{P})$ containing species originating from engine oil additives [1]. The effect of $\mathrm{P}$ on the catalyst deactivation mechanism is not completely understood [2], and hence an attempt is made to unravel the deactivation mechanism caused by $\mathrm{P}$ using operando spectroscopy. The results reveal the occurrence of Pd redox cycle during the temporal analysis of the fresh $(\mathrm{Pd} / \mathrm{Al})$ and $\mathrm{P}$ aged $(7.5 \mathrm{P} / \mathrm{Pd} / \mathrm{Al})$ catalysts by $\mathrm{CO} / \mathrm{NO}$ pulses. However on $7.5 \mathrm{P} / \mathrm{Pd} / \mathrm{Al}$, reactions involving Pd redox cycle are not as efficient as on Pd/Al as evident from ED-EXAFS, MS and DRIFTS data. Additionally, DRIFTS data show a larger population of isocyanate species (reflected by bands at 2180,2228 and $2250 \mathrm{~cm}^{-1}$ ) on $\mathrm{Pd} / \mathrm{Al}$ than on $7.5 \mathrm{P} / \mathrm{Pd} / \mathrm{Al}$ that exhibits only a single band at $2260 \mathrm{~cm}^{-1}$. The missing low frequency bands at 2180 and $2228 \mathrm{~cm}^{-1}$ are attributed to $\mathrm{P}$ that clogs the surface $\mathrm{Pd}$ sites and reacts with support alumina to form $\mathrm{AlPO}_{4}$ species, respectively. Consequently, the TWC efficiency of $\mathrm{P}$ aged catalyst is decreased.

[1] S.K. Matam, A. Weidenkaff, et al., Catal. Today 2012, 184, 237.

[2] S.K. Matam, A. Weidenkaff, et al., Catal. Today 2013, 205, 3. 
Catalysis Science Engineering

\section{Terahertz pulse induced catalytic} decomposition of $\mathrm{CO}$ on metallic surfaces

Tibor Nagy and Markus Meuwly

Department of Chemistry, University of Basel Klingelbergstrasse, 80, 4056 Basel, Switzerland

Combining catalysis with mode specific vibrational excitation for the selective rate enhancement of chemical reactions can open new perspectives in controlling chemical reactions [1] and can revolutionize chemical industry. Pursuing this idea, in recent experiments at Swiss Light Source in PSI [2], CO molecules adsorbed on $\mathrm{Pt}$ nanoparticles were bombarded by energetic $\mathrm{THz}$ pulses. The aim was to characterize the intermode coupling between THz-induced wagging and IR-stretching of $\mathrm{CO}$, which is a prerequisite for the $\mathrm{THz}$ pulse initiated decomposition of $\mathrm{CO}$.

For the theoretical confirmation of the mode-coupling, BMK density functional calculations (LANL2D, 6-31G*) were carried out for Pt7-3-CO cluster. A significant negative anharmonic coupling between the $\mathrm{CO}$ stretching and the hindered translational modes was found by vibrational second-order perturbation theory (VPT2). Also a large red shift of the stretching mode was found by applying displacements along the hindered translational mode corresponding to high excitations. These findings imply that excitation of frustrated translation significantly weakens the $\mathrm{CO}$ bond and indeed can promote the surface catalytic reaction.

Force-field parameterization of $\mathrm{CO}$ vibrations and atomic charges $(\mathrm{C}, \mathrm{O})$ were determined and the cluster was embedded into the (111) surface of a Pt slab. In a molecular dynamics (MD) simulation of the system at $300 \mathrm{~K}$, a THz pulse of normal incidence was applied with an electric field strength matching experimental values. The pulse induced very large amplitude wagging, which did not relax

In our upcoming MD studies, we will investigate other metallic surfaces $(\mathrm{Ni}$, $\mathrm{Rh}, \mathrm{Pd}$ ), on which the dissociative adsorption of $\mathrm{CO}$ is energetically less unfavourable. We will apply Adiabatic Reactive Molecular Dynamics (ARMD) simulation technique [3] to investigate the dynamics of $\mathrm{THz}$ pulse induced dissociation of $\mathrm{CO}$.

[1] H. Ogasawara et al, Int. Free Electron Laser Conf., 2005, Stanford

[2] B. D. Patterson et al, Chimia, 2011, 65, 323.

[3] J. Danielsson, M. Meuwly, J. Chem. Theory. Comput. 2008, 4, 1083 within 50ps, proving that phonon excitation is to slow too prevent the dissociation.

Catalysis Science Engineering

CSE54

\section{Iridium-titanium oxide as a stable support for Pt catalyst in PEFC cathodes}

Tobias Binninger, Emiliana Fabbri, Rüdiger Kötz, and Thomas J. Schmidt

Paul Scherrer Institut, 5232 Villigen PSI, Switzerland

In automotive polymer electrolyte fuel cell (PEFC) applications, the cathode potential can reach values up to $1.5 \mathrm{~V}$ during start/stop conditions [1]. This constitutes a major problem for state-of-the-art cathodes made of carbon supported platinum nanoparticles, because at cell voltages above $1.1 \mathrm{~V}$ severe carbon corrosion (oxidation) occurs [1]. The consequence is a detachment of Pt catalyst nanoparticles, and thus a strong degradation of PEFC performance. Conductive metal oxides are a possible alternative to the conventional carbon for supporting the Pt catalyst. Their property of being in a highly oxidized state makes them promising candidates to resist the oxidative environment at the PEFC cathode side.

We have studied the stability and performance properties of $\mathrm{Pt}$ nanoparticles supported on iridium-titanium oxide $\left(\operatorname{Ir}_{\mathrm{x}} \mathrm{Ti}_{1-\mathrm{x}} \mathrm{O}_{2}\right)$. The electrochemical stability of the bare support and of the supported Pt catalyst was tested by cyclic voltammetry in $0.1 \mathrm{M} \mathrm{HClO}_{4}$ using the thin-film rotating disk electrode technique where the catalyst is drop-coated onto the glassy carbon disks of the working electrode. Start/stop conditions in PEFC operation have been simulated by performing 1000 potential cycles between $0.5 \mathrm{~V}$ and $1.5 \mathrm{~V}$ versus a hydrogen reference electrode (RHE). The results to be presented confirm the high stability of the $\operatorname{Ir}_{\mathrm{x}} \mathrm{Ti}_{1-\mathrm{x}} \mathrm{O}_{2}$ material, and the suitability of this metal oxide as a stable support for the Pt catalyst in PEFC cathodes. This work is supported by CCEM Switzerland and Umicore AG \& Co KG within the project DuraCat.

[1] F.N. Büchi, M. Inaba, and T.J. Schmidt, editors. Polymer Electrolyte Fuel Cell Durability, Springer, 2009.

Catalysis Science Engineering

Comparison of ceramic foams and honeycombs as substrates for $\mathrm{Pt} / \mathrm{Al}_{2} \mathrm{O}_{3}$ diesel oxidation catalysts

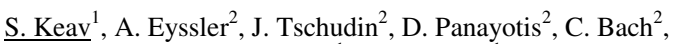
A. Weidenkaff ${ }^{1}$, S.K. Matam ${ }^{1}$

Empa: ${ }^{1}$ Lab. for Solid State Chemistry and Catalysis; ${ }^{2}$ Internal Combustion Engines Lab., CH-8600 Dübendorf, Switzerland

In the lean burn diesel engine exhaust after treatment system, the diesel oxidation catalyst (DOC) plays an important role as it oxidizes $\mathrm{CO}$ and unburned hydrocarbons as well as $\mathrm{NO}$ into $\mathrm{CO}_{2}$ and $\mathrm{NO}_{2}$, respectively. The latter modifies the $\mathrm{NO} / \mathrm{NO}_{\mathrm{x}}$ ratio which affects the rate of $\mathrm{NO}_{\mathrm{x}}$ reduction in the successive selective catalytic reduction of $\mathrm{NO}_{\mathrm{x}}(\mathrm{SCR})$ system [1]. In the current technology, the DOC is coated on a cordierite honeycomb substrate. However, ceramic foams have attracted much attention in the recent past as alternative substrates to monoliths due to their improved heat and mass transportation and hence improved catalytic efficiency [2,3].

In this work, $400 \mathrm{cpsi}$ (channels per square inch) cordierite monoliths and 10 ppi (pores per inch) ceramic foams were coated with $\mathrm{Pt} / \mathrm{Al}_{2} \mathrm{O}_{3}$ using different in-house developed coating protocols. The catalytic activity of the coated substrates was determined in a simulated diesel exhaust. By comparison, slurry coating procedure yields monolith substrates with better activity than those obtained by sol-gel method. The catalytic activity of such monoliths is similar to that of a commercial reference DOC monolith with a comparable noble metal loading. Slurry-coated foams surprisingly show lower activity than their monolith counterparts. Further complementary experimental and theoretical studies are in progress to understand the catalytic activity of foams and monoliths from fundamental chemical engineering aspects.

[1] S.K. Matam, E.V. Kondratenko, et al., Appl. Catal. B, 2013, 129, 214.

[2] F.C. Patcas, G.I. Garrido, et al., Chem. Eng. Sci., 2007, 62, 3984.

[3] P. Ciambelli, V. Palma, E. Pallo, Catal. Today, 2010, 155, 92.
Investigation of $\mathrm{LaCoO}_{3}$ based perovskite type oxides for methanol steam reforming: Effect of $B$ site substitution with $\mathrm{Pd}$ and/or $\mathrm{Zn}$

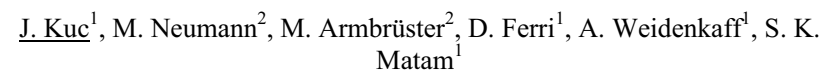

${ }^{1}$ Empa, Swiss Federal Laboratories for Materials Science and Technology, Laboratory for Solid State Chemistry and Catalysis, Überlandstrasse 129, CH-8600 Dübendorf, Switzerland

${ }^{2}$ Max-Planck-Institut für Chemische Physik fester Stoffe, Nöthnitzer Str. 40, D-01187 Dresden, Germany

Given the potential of methanol steam reforming (SRM) for clean $\mathrm{H}_{2}$ supply for mobile and stationary applications, an intense collaborative research has been under taken under the COST Action (CM090) [1]. Part of these efforts we have investigated $\mathrm{LaCoO}_{3}$ perovskite type oxides by partial substitution of Co (B site) with Pd and/or Zn for SRM. The perovskite-type oxides were prepared by the amorphous citrate method and were characterized by various physico-chemical techniques. The characterization results indicate that the reducibility of $\mathrm{LaCoO}_{3}$ altered significantly by substitution. The reduction events (as evident from TPR) shift progressively to lower temperatures with increasing $\mathrm{Pd}$, in line with in situ XRD. Variations in the B site substitution level, $\mathrm{CH}_{3} \mathrm{OH}$ to $\mathrm{H}_{2} \mathrm{O}$ ratio and reductive pre-treatment temperature strongly influence the catalytic SRM activity and $\mathrm{CO}_{2}$ selectivity of $\mathrm{LaCoO}_{3}$. The $\mathrm{CO}_{2}$ selectivity patterns as a function of temperature over these perovskites are quite complex and consists of two distinct maxima. The low temperature maximum can be attributed to the $\mathrm{Pd} / \mathrm{Zn}$ interactions and is dependent on the B-site substitution level. Whereas the high temperature selectivity maximum seems to be independent of the B site substitution and it could be attributed to the temperature dependent bulk perovskite structure.

[1] Matthias Friedrich, Detre Teschner, Axel Knop-Gericke, Marc Armbrüster, J. Catal. 2012, 285, 41 . 
Catalysis Science Engineering

CSE57

\section{A Hydrolase with a Twist}

Valentin Köhler, Thomas R. Ward

University of Basel, Spitalstr. 51, 4056 Basel, Switzerland

Dienes as steering ligands for asymmetric catalysis are most prominently represented in rhodium catalyzed 1,4 additions [1]. Carreira and later Jäschke used $\{\operatorname{Ir}($ diene $)\}$ complexes as catalysts for the asymmetric allylic subsitution reaction [2-3]. By incorporation of a biotinylated Ir-diene within streptavidin we generated an artificial hydrolase for the conversion of racemic allylic acetate 1 to enantioenriched allylic alcohol 2.

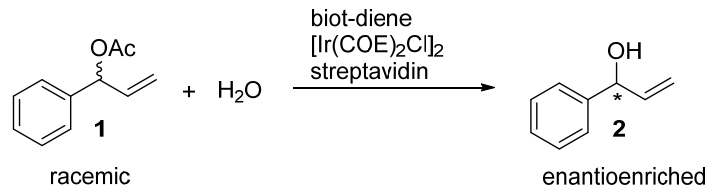

biot-diene $=$ biotinylated diene ligand

[1] R. Shintani, T. Hayashi, Aldrichimica Acta 2009, 42, 31.

[2] C. Fischer, C. Defieber, T. Suzuki, E. M. Carreira, J. Am. Chem. Soc 2004, 126, 1628.

[3] P. Fournier, R. Fiammengo, A. Jäschke, Angew. Chem. Int. Ed. 2009 $48,4426$.
Catalysis Science and Engineering

CSE58

How Selective are Probe Molecules for Defect Sites on $\gamma$-Alumina?

Martin Schwarzwälder ${ }^{1}$, Aleix Comas-Vives, Christophe Copéret ${ }^{1}$, Philippe Sautet $^{2}$

${ }^{1}$ ETH Zürich, Department of Chemistry, Wolfgang Pauli Strasse 10, CH8093 Zürich (Switzerland)

${ }^{2}$ Université de Lyon, Institut de Chimie de Lyon, CNRS, École Normale Supérieure de Lyon, 46 allée d'Italie, F-69364 Lyon Cedex 07 (France)

Aluminas in different transitions are widely used as catalysts or catalyst supports in heterogeneous catalysis. These transition aluminas exhibit Al-III sites that are active for various molecules, including $\mathrm{H}_{2}$ and alkanes. We have proposed structure of such active sites as well as some mechanistic studies towards hydrogen or methane. [1]
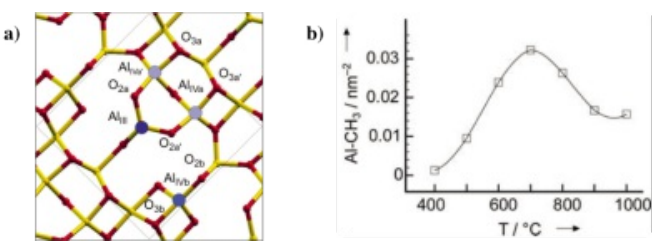

a) Surface $\mathrm{Al}$ sites on a bare 110 surface as an illustration. b) Titration of defect sites by methane as a function of thermal treatment.

Here we discuss the reactivity of these sites towards haloginated hydrocarbons $\left(\mathrm{RCH}_{2} \mathrm{X}\right.$, with $\mathrm{X}=\mathrm{F}$ and $\mathrm{Cl}, \mathrm{R}=\mathrm{CH}_{3}$ or $\left.\mathrm{CH}_{2} \mathrm{CH}_{3}\right)$ through a combined experimental and computational approaches.

[1] Wischert et al. Angew. Chem. Int. Ed. 2011, 50, 3202. Rascón et al., Chem. Sci. 2012, 2, 1449. Wischert et al., J. Am. Chem. Soc., 2012, 134, 14430.

\section{Dependence of Electrochemical $\mathrm{CO}_{2}$ Reduction products on Metal} Electrodes in Organic Media

\section{Yeonji Oh, Xile Hu}

Laboratory of Inorganic Synthesis and Catalysis, Institute of Chemical Sciences and Engineering, Ecole Polytechnique Fédérale de Lausanne, CH-1015, Switzerland

The electrochemical conversion of $\mathrm{CO}_{2}$ into hydrocarbons and useful products is an attractive proposition for providing an alternative solution to both current energy crisis and environmental issues. ${ }^{1,2}$ Herein, we show that in low-temperature organic media, simple metal (M) electrodes are highly active toward $\mathrm{CO}_{2}$ reduction to $\mathrm{CO}$, oxalate and formate. A technique to fabricate modified- $\mathrm{Pb}$ working electrode was investigated during the process of screening several metal compounds to explore their catalytic activity. The modified $\mathrm{M}-\mathrm{Pb}$ working electrode showed a stable activity in a series of polarization measurement within a wide range of potential window. In acetonitrile and DMF both, the current density of $\mathrm{CO}_{2}$ reduction increases significantly with lowering the temperature. The ratio of reduction products are also changed by lowering temperature. Furthermore, the efficiency and selectivity of $\mathrm{CO}_{2}$ reduction depend with the increase of water concentration in organic media and the potential as well. Faradaic efficiencies of the metal catalyst in these conditions are higher than $90 \%$ (efficiencies of $100 \%$ have been measured in some conditions). Further characterization and application of this catalyst are currently underway.

[1] K. Caldeira, A. K. Jain and M. I. Hoffert, Science, 2003, 299, 2052-2054.

[2] Y. Oh and X. Hu, Chem. Soc. Rev., 2013, 42, 2253-2261. 